\title{
Potato virus Y HCPro Localization at Distinct, Dynamically Related and Environment-Influenced Structures in the Cell Cytoplasm
}

\author{
Francisco del Toro, ${ }^{1}$ Fátima Tena Fernández, ${ }^{1}$ Jens Tilsner, ${ }^{2,3}$ Kathryn M. Wright, ${ }^{2}$ Francisco Tenllado, ${ }^{1}$ \\ Bong Nam Chung, ${ }^{4}$ Shelly Praveen, ${ }^{5}$ and Tomas Canto ${ }^{1}$ \\ ${ }^{1}$ Environmental Biology Department, Centro de Investigaciones Biológicas, CIB-CSIC, Ramiro de Maeztu 9, 28040 Madrid; \\ ${ }^{2}$ The James Hutton Institute, Cell and Molecular Sciences, Invergowrie, Dundee, DD2 5DA, U.K.; ${ }^{3}$ Biomedical Sciences \\ Research Complex, University of St Andrews, Fife KY16 9ST, Scotland, U.K.; ${ }^{4}$ National Institute of Horticultural \& Herbal \\ Science, Agricultural Research Center for Climate Change, 281, Ayeon-ro, Jeju, 690-150, Jeju Island, Republic of Korea; \\ ${ }^{5}$ Division of Plant Pathology, Indian Agricultural Research Institute, 110012 New Delhi, India
}

Submitted 27 May 2014. Accepted 25 July 2014.

\begin{abstract}
Potyvirus HCPro is a multifunctional protein that, among other functions, interferes with antiviral defenses in plants and mediates viral transmission by aphid vectors. We have visualized in vivo the subcellular distribution and dynamics of HCPro from Potato virus $Y$ and its homodimers, using green, yellow, and red fluorescent protein tags or their split parts, while assessing their biological activities. Confocal microscopy revealed a pattern of even distribution of fluorescence throughout the cytoplasm, common to all these modified HCPros, when transiently expressed in Nicotiana benthamiana epidermal cells in virus-free systems. However, in some cells, distinct additional patterns, specific to some constructs and influenced by environmental conditions, were observed: i) a small number of large, amorphous cytoplasm inclusions that contained $\alpha$-tubulin; ii) a pattern of numerous small, similarly sized, dot-like inclusions distributing regularly throughout the cytoplasm and associated or anchored to the cortical endoplasmic reticulum and the microtubule (MT) cytoskeleton; and iii) a pattern that smoothly coated the MT. Furthermore, mixed and intermediate forms from the last two patterns were observed, suggesting dynamic transports between them. HCPro did not colocalize with actin filaments or the Golgi apparatus. Despite its association with MT, this network integrity was required neither for HCPro suppression of silencing in agropatch assays nor for its mediation of virus transmission by aphids.
\end{abstract}

Members of the genus Potyvirus are filament-shaped, plussense RNA viruses that express a single polyprotein that undergoes proteolytic cleavage to generate the final products, although one small essential gene $(P 3 N-P I P O)$ expresses itself via translational frameshifting (Chung et al. 2008). The proteases involved in this processing are the $\mathrm{P} 1$ protein, which is

F. del Toro and F. Tena Fernández contributed equally to this work.

Corresponding authors: S. Praveen; E-mail: shellypraveen@hotmail.com; and T. Canto; E-mail: tomas.canto@cib.csic.es

*The $\boldsymbol{e}$-Xtra logo stands for "electronic extra" and indicates that three supplementary figures are published online.

(C) 2014 The American Phytopathological Society the first product from the polyprotein that detaches itself at its $\mathrm{C}$ terminus from the following HCPro (Verchot and Carrington 1995a; Verchot et al. 1991): HCPro, a papain-like protease that detaches itself at its $\mathrm{C}$ terminus from the rest of the polyprotein (Carrington and Herndon 1992); and the small nuclear inclusion body protein (NIa), which cleaves the remaining sites (Carrington et al. 1988; García et al. 1989). Potyvirus polyprotein translation is thought to be closely coupled to viral replication which, as in many RNA viruses, takes place in replicative complexes associated with membrane vesicles that originate from the endoplasmic reticulum (ER). In the specific case of potyviruses, these vesicles are transported from the ER via actin filaments toward the chloroplasts for enhanced replication (Wei and Wang 2008; Wei et al. 2013). The transport of potyviral protein products from replication-translation vesicle factories to other parts of the cell may be mediated by routes such as the secretory pathway or the cell microtubules (MT) or microfilaments, although our knowledge of these processes is still fractionary (Sorel et al. 2014).

HCPro is a multifunctional protein that, in addition to its protease activity, is involved in the suppression of the antiviral gene silencing defenses of the host, among other functions (Anandalakshmi et al. 1998, Brigneti et al. 1998; Canto et al. 2002; Johansen and Carrington 2001; Rajamäki et al. 2005; Valli et al. 2006). It is also required in the transmission of potyviruses by their insect aphid vectors; hence its original name of "helper component" (Govier and Kassanis 1974). HCPro has been traditionally divided into three domains: the $\mathrm{N}$-terminal domain associated with aphid transmission (Blanc et al. 1997; Canto et al. 1995b) and its interaction with proteasomal units (Jin et al. 2007a; Sahana et al. 2014), the central domain associated with the suppression of silencing function (Shiboleth et al. 2007), and the C-terminal domain of the protein that harbors its protease activity (Carrington and Herndon 1992) and interaction domains to plant HIP2-like MT-associated proteins (Guo et al. 2003; Haikonen et al. 2013a and b).

Soluble HCPro from several potyviruses extracted from infected plants has been shown by size chromatography to be formed mainly by homodimers and further aggregates (Plisson et al. 2003; Ruíz-Ferrer et al. 2005, Tena et al. 2013; Thornbury et al. 1985), which could be relevant to some of the biological functions of the protein. Self-interactions of HCPros have also been demonstrated by yeast two-hybrid assays (Y2H) (Urcuqui- 
Inchima et al. 1999) or visualized in the plant cell cytoplasm by bimolecular fluorescence complementation (BiFC) (AlaPoikela et al. 2011; Sahana et al. 2012; Zheng et al. 2011; Zilian and Maiss 2011).

Despite being one of the most studied plant virus proteins, relatively little is known about the precise modes by which HCPro undertakes these two principal functions of silencing suppression and mediation of viral transmission by vectors. As regards silencing suppression, it is known that HCPro interacts in vitro with long RNAs (approximately 200 nucleotides) and small RNAs (Chapman et al. 2004; Lakatos et al. 2006; Maia and Bernardi 1996; Mangrauthia et al. 2009; Mérai et al. 2006; Shiboleth et al. 2007; Urcuqui-Inchima et al. 2000) but at protein/RNA molar ratios much higher than the 2:1 characterized for the $2 \mathrm{~b}$ and P19 suppressors of Tomato bushy stunt virus (TBSV) (González et al. 2012; Vargasson et al. 2003) and $\mathrm{Cu}$ cumber mosaic virus (CMV), thus making it unlikely that HCPro interferes with antiviral silencing in the same way as P19 and 2b do; that is, by means of sequestering small interfering RNAs. On the other hand, HCPro interacts in vitro with the RNA methyltransferase HEN-1, inhibiting it (Jamous et al. 2011). Suppressor activity of HCPro also seems influenced by the P1 protein (Canto et al. 2002; Johansen and Carrington 2001; Pruss et al. 1997; Rajamäki et al. 2005; Valli et al. 2006; Verchot and Carrington 1995a and b). That P1 detachment is essential for HCPro suppressor activity in agropatch assays was recently demonstrated (Pasin et al. 2014). However, a direct role for P1 on HCPro suppressor activity either as cofactor or by influencing its conformation during translation to improve its stability has been be excluded and it appears, instead, that its effect on HCPro can be explained by cis-acting elements that favor HCPro translation in the upstream presence of P1, without ruling out a possible role of $\mathrm{P} 1$ in protecting HCPro from degradation (Tena et al. 2013).

As regards viral transmission by vectors, HCPro is required to be taken by the vector prior to or simultaneously with virions for transmission to occur. HCPro can interact with the homologous viral coat protein in vitro, as well as in plant extracts (Blanc et al. 1997; Roudert-Tavert et al. 2002). Of not clear significance to transmission, HCPro has been found to be present at one end of a tiny minority (less than $3 \%$ ) of Potato virus $Y$ (PVY) and Potato virus A (PVA) virions (Torrance et al. 2006).

HCPro interaction with plant factors and cytoplasmic structures involved in processes other than gene silencing is extensive: it binds a host rgs-CaM factor, which directs its degradation through autophagy (Nakahara et al. 2012) to the Arabidopsis thaliana transcription factor RAV2 (Endres et al. 2010) to components of the proteasome, which participate in another type of antiviral defense (Ballut et al. 2005; Dielen et al. 2011; Sahana et al. 2012), with translation initiation factors (AlaPoikela et al. 2011; Freire 2014), with chloroplast factors (Cheng et al. 2008; Jin et al. 2007b), and with MT-binding HIP2-type proteins (Guo et al. 2003; Haikonen et al. 2013).

As regards the subcellular loci where several HCPro functions and interactions take place, early electron microscopy immunolocalization studies situated PVY HCPro in the cytoplasm of fixed infected mesophyll cells forming amorphous inclusions (Baunoch et al. 1990). Studies using fixed cowpea protoplasts found HCPro from Cowpea aphid-borne mosaic virus (CABMV) diffused throughout the cytoplasm (Mlotshwa et al. 2002). In live tissues, HCPro from Turnip mosaic virus (TuMV) tagged with green fluorescent protein (GFP) was also found to localize to the cytoplasm of epidermal Nicotiana benthamiana cells as filaments, around the nucleus, and in what could be the ER; whereas, in protoplasts from transgenic $N$. benthamiana plants expressing GFP targeting the ER (line 16c) (Ruíz et al. 1998), untagged HCPro from TuMV induced morphological changes in the ER structure, suggesting an interaction between HCPro and this structure (Zheng et al. 2011). Furthermore, PVA HCPro interaction with the host HIP2 factor has been visualized by BiFC, coating in vivo MT (Haikonen et al. 2013b). Thus, evidence from the literature with regard to HCPro subcellular targets and its accumulation originates from different potyviruses and hosts and is diverse, pointing at different subcellular structures and features.

In this work, we have used HCPros modified with fluorescent proteins to visualize the protein in the living cell and its dynamics in vivo, while characterizing their biological properties using activity assays. Our initial hypothesis was that this approach could allow us to link observations on subcellular targets of HCPro to its biological functions, by disrupting those targets and assessing their effect on the activity assays. Unlike previous works by others, we carried out a comparative study on the subcellular distribution of PVY HCPro using different, functionally characterized constructs fused to GFP and yellow and red fluorescent protein (YFP and RFP, respectively) tags or their split halves to obtain a more comprehensive picture of HCPro subcellular whereabouts and dynamics. We found that, in a virus-free transient expression system, HCPro distributed evenly throughout the cytoplasm. However, for some constructs and in some cells, we could also identify accumulation in distinct structures: as a few large, irregular inclusions; as numerous evenly distributed dot-shaped inclusions of similar size associated with both cortical ER and MT; and, finally, colocalizing extensively with the MT cytoskeleton. Although, in some individual cells, localization at one particular structure was prevalent, in other cells mixed and intermediate patterns could be found, suggesting that they evolved from one into another and, thus, were dynamically linked. Furthermore, the presence of these structures was influenced by environment stresses. We also tested the need for HCPro functions of its interactions with defined subcellular structures by disrupting them and performing biological activity assays. Potential biological implications of our results are discussed.

\section{RESULTS}

\section{Fluorescent tags affect HCPro biological activities to different degrees.}

To study the subcellular distribution of PVY HCPro in vivo, we tagged it with fluorescent proteins or their split parts (Fig. 1). C-terminal tagging of HCPro included GFP and monomeric (m)RFP (Fig. 1, constructs P1-HCPro-GFP and P1-HCPromRFP, respectively). In these $\mathrm{C}$-terminal fusion constructs, the second glycine at the HCPro protease cleavage site (tyrosine$\mathrm{X}$-valine-glycine/glycine) had been replaced by tyrosine-arginine-valine-glycine/alanine, a motif shown previously not to be cleaved by Tobacco etch virus (TEV) HCPro in rabbit reticulocyte lysates (Carrington and Herndon 1992). However, Western blot analysis of the expressed proteins showed that both had the same size as the native protein (Supplementary Fig. S1, Western blot, third and fourth lanes versus second lane). The most likely explanation for these data is that, after translation of the fusion product, the fluorescent tags became detached from HCPro. Thus, our C-terminal tagging approach proved inefficient to its purpose.

N-terminal taggings of HCPro with GFP, mRFP, split (s)YFP (sYN and sYC), and split monomeric (sm)RFP (sRN and sRC) parts (Fig. 1) were stable, and fusion proteins had the expected size in Western blots (Fig. 2; data not shown). All the constructs had an additional hexahistidine motif in frame, located either at the end of the $\mathrm{N}$ terminus of the fusion construct (plus a starting methionine) in the case of GFP- or sYFP- 
tagged constructs, or between the fluorescent tag and HCPro in the case of mRFP- or smRFP-tagged constructs (Fig. 1).

Suppression of the silencing of a free GFP reporter by these $\mathrm{N}$-fusion constructs in agroinfiltration patch assays showed that tags affected this HCPro activity to varying degrees. Suppression was very weak in both of the GFP-tagged constructs (Fig. 2A, leaves in the upper panel and Western blot panel). By contrast, the sYFP-tagged constructs showed stronger suppressor activities; in particular, construct $6 \mathrm{x}-\mathrm{s} Y \mathrm{~N}-\mathrm{HCPro}$ or when both $\mathrm{N}$ - and C-terminal parts were combined. The accumulation of construct 6x-YC-HCPro was also weak in infiltrated tissue but it rose when it was coexpressed with construct $6 \mathrm{x}-\mathrm{YN}-\mathrm{HCPro}$ (Fig. 2A, leaves in the middle panel, and Western blot panels). In contrast to the GFP constructs, the mRFP-tagged construct displayed suppression of silencing activity (Fig. 2B); in particular, that from the combined smRFP-tagged constructs (Fig. 2C). For this high preservation of suppressor activity and for their good fluorescence response under confocal microscopy, the use of BiFC smRFP-tagged HCPro constructs was preferred, when possible, in our in vivo subcellular localization studies.

Regarding mediation of virus transmission by aphids, we tested 6x-HCPro and 6x-GFP-HCPro after their large-scale purification from plant tissue infected with PVX-P1-6x-HCPro or with PVX-P1-6x-GFP-HCPro, respectively. Although purified 6x-HCPro successfully mediated transmission of PVY virions in aphid membrane feeding tests, 6x-GFP-HCPro did not (Supplementary Fig. S2). Therefore, the tagging of HCPro with GFP had a severe negative effect on both activities, silencing suppression in agropatch assays and mediation of virus transmission by insects. Tagging with mRFP and smRFP was less detrimental to suppressor activity. These two latter constructs were not tested for aphid transmission activity.

\section{HCPros with fluorescent tags accumulate}

in distinct yet dynamically related as well as environment-influenced structures in epidermal cells.

We used confocal microscopy of our N-terminal tagged constructs to visualize HCPro in subcellular structures within liv-

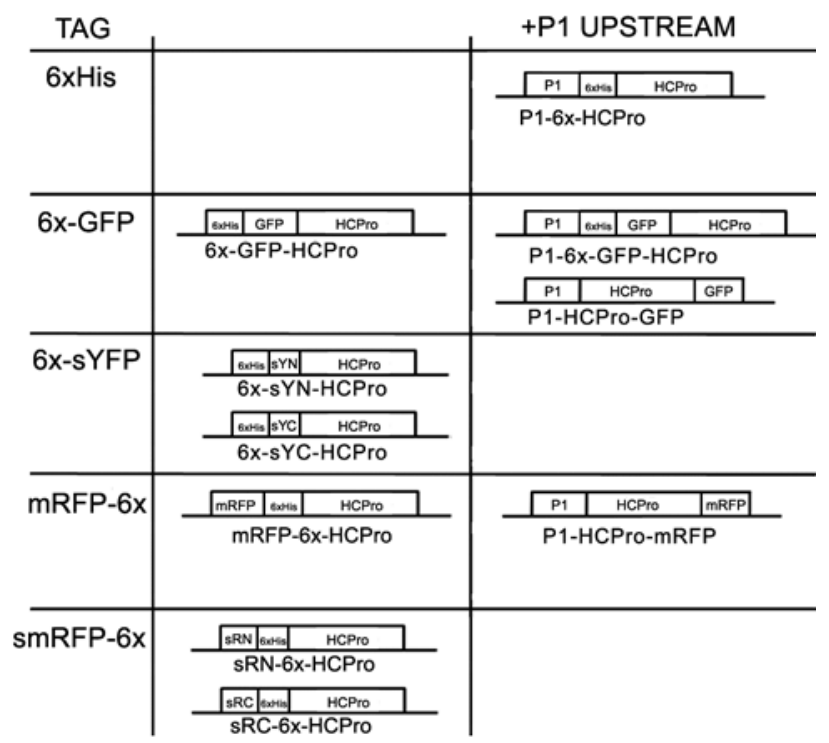

Fig. 1. N-terminal and C-terminal tagging of HCPro for fluorescence studies in vivo. Schematic representation of the different constructs tagged with green fluorescent protein (GFP), $\mathrm{N}$-terminal and C-terminal split yellow fluorescent protein parts ( $\mathrm{sYN}$ and $\mathrm{sYC}$, respectively), monomeric red fluorescent protein (mRFP), or $\mathrm{N}$-terminal and $\mathrm{C}$-terminal split mRFP parts (sRN and $\mathrm{sRC}$, respectively) at either the $\mathrm{N}$ or the $\mathrm{C}$ terminus of HCPro, and in the upstream presence or absence of P1 protein during translation. ing cells. We had GFP and mRFP-tagged constructs as well as constructs that were tagged with split parts of either YFP (sYFP) or mRFP (smRFP). In the latter two cases, visualized fluorescence would correspond only to the interacting homodimers of HCPro that had complementary tags (sYN + sYC tags; $\mathrm{sRN}+\mathrm{sRC}$ tags) as a result of BiFC.

Confocal imaging of single epidermal cells showed that, in many cells, fluorescence derived from constructs P1-6x-GFPHCPro and mRFP-6x-HCPro distributed smoothly throughout the cytoplasm, negatively staining some unidentified vesicle structures (Fig. 3, upper panels). In addition, large irregular inclusions were observed in the case of the GFP-tagged construct but not in the case of the mRFP-tagged one (Fig. 3, upper left panel, arrows)

Confocal imaging at low magnification covering fields of approximately $20 \mathrm{~N}$. benthamiana epidermal cells transiently expressing GFP- or sYFP-tagged HCPros showed, in both cases, a similar pattern of distribution, in which most of the fluorescence appeared distributed throughout the cytoplasm; in particular, as the large inclusions aforementioned of irregular or amorphous shape. Interestingly, the transient presence of heterologous suppressors of silencing, provided with the intention of boosting the accumulation of HCPro, such as TBSV P19 or the CMV 2b protein, had the effect of reducing both the number and size of these irregular inclusions throughout the cytoplasm without increasing the overall accumulation of HCPro (Fig. 3, second and third rows of panels from the top, respectively). At the same low magnification level, a few irregular inclusions were also found in smRFP-tagged HCPro, usually one or two inclusions per cell, much less than those found in GFP- or split YFP-tagged constructs. The presence of heterologous suppressors P19 or $2 \mathrm{~b}$ was also detrimental to their number and size (Fig. 3, fourth row of panels from the top; data not shown). These data show that the formation of large irregular inclusions can be influenced by factors from the environment in which the constructs are expressed.

In some epidermal cells, instead of the diffuse distribution of fluorescence throughout the cytoplasm, other different and distinct patterns were found: fluorescence from smRFP-tagged constructs was found in some cells distributed as dots of similar size, regularly positioned in a mesh pattern. In some of these cells, the dots appeared interconnected by filaments of red fluorescence of a similar diameter. In other cells, only the smooth red filaments were visible (Fig. 4, second row of panels from the top). The presence of fluorescent filaments connecting dots was also demonstrated for mRFP-, sYFP-, and GFP-tagged HCPros (Fig. 4, upper and lower rows of panels, respectively; data not shown). We found cells harboring these dots and filaments plus their intermediate forms mainly but not exclusively when infiltrated tissue was exposed to some stresses; in particular, volatile components from common nail varnish used as sealant at the edges of the infiltrated plant tissue several minutes prior to confocal viewing. It must be highlighted that none of the epidermal cells imaged had direct contact with the varnish, they were fully turgent, and they had their subcellular structures visually unaltered (Fig. 5, integrity of the ER). Cells with filaments could also sometimes be found in tissue treated with saturated $\mathrm{CO}_{2}$ atmosphere (data not shown). By contrast, 50 aphids left overnight on the infiltrated patch before confocal viewing failed to induce the filament pattern (data not shown). These responses were specific to HCPro constructs, because transiently expressed free mRFP or split mRFP-tagged $2 \mathrm{~b}$ protein dimers did not alter their diffuse cytoplasmic and nuclear localization under the same stresses (data not shown; Supplementary Fig. S3). We did not identify which component of the nail varnish was responsible for the response. For example, one of its volatile components, 
n-butyl acetate, can be a component in insect pheromones. However, we tested the two components (n-butyl acetate and ethyl acetate) separately and neither induced the HCPro filament distribution pattern in our experimental conditions (data not shown).

To identify whether the HCPro-derived fluorescence as dots or filaments or as large inclusions colocalized with defined subcellular structures, we used transgenic $N$. benthamiana plants that constitutively expressed GFP fused to A. thaliana $\alpha$-tubulin (Tua-GFP plants) (Gillespie et al. 2002), GFP targeting the cortical ER (line 16c) (Ruíz et al. 1998), and a Lifeact TagRFP fusion targeting actin. To visualize the Golgi apparatus, we also transiently overexpressed a binary vector expressing mCherry protein with a targeting signal to this structure (Nelson et al. 2007). In the green-fluorescing backgrounds of the $16 \mathrm{c}$ and Tua-GFP transgenic plants, we transiently expressed split red HCPro constructs and detected the BiFC-derived fluorescence of the interacting homodimers. As we had previously
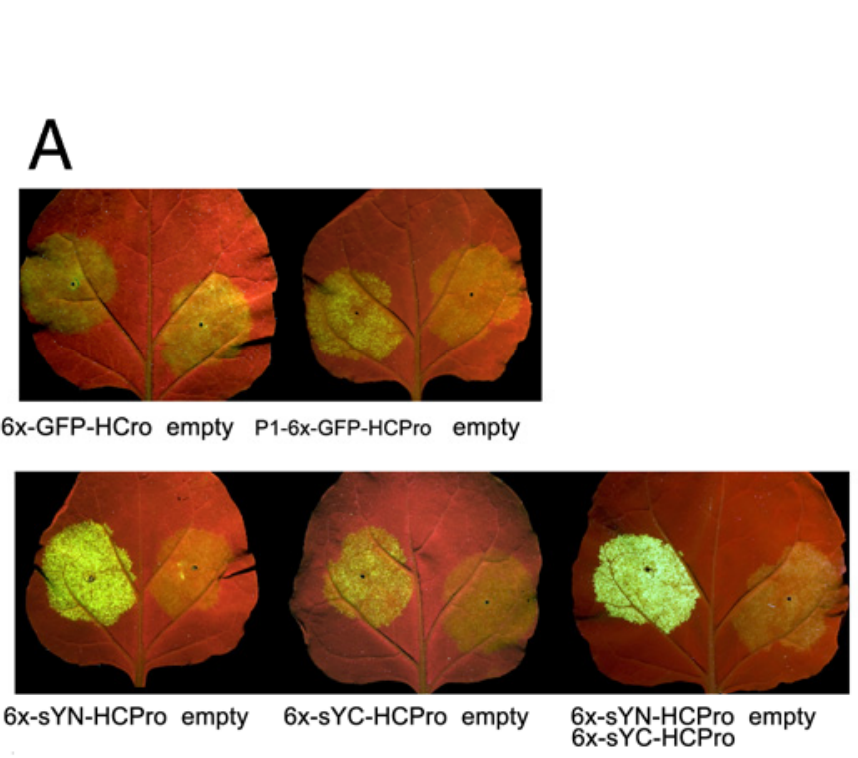

6x-GFP-HCro empty P1-6x-GFP-HCPro empty
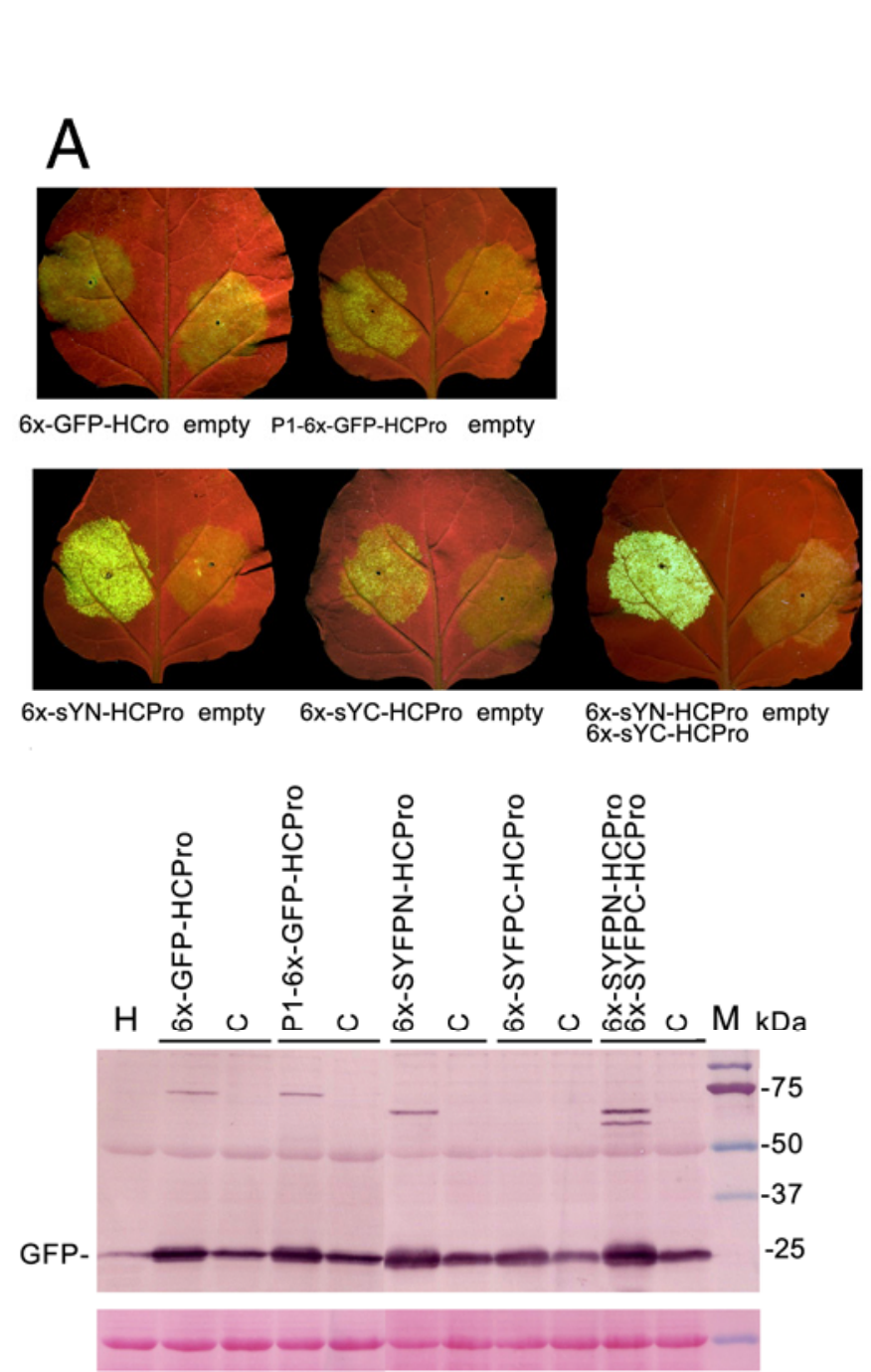

seen in nontransgenic plants (Fig. 4), we could find fluorescence from sRN-6x-HCPro + sRC-6x-HCPro BiFC distributing as dots, filaments, or intermediates in some epidermal cells of both stress-treated 16c and Tua-GFP plants (Fig. 5). In $16 \mathrm{c}$ plants, the cortical ER fluoresced green in a characteristic polygonal net (Fig. 5, upper green and overlay panels). Although the BiFC-derived red fluorescence from interacting HCPros did not overlap with that from the ER, images showed that the red dots appeared nevertheless anchored somehow or linked to the ER scaffold (Fig. 5, overlay panels in upper row). The red filaments seemed, by contrast, unrelated to the ER structure (Fig. 5, overlay panel in second row from the top). In stressed Tua-GFP plants, many epidermal cells displayed a filamentous green fluorescent MT cytoskeleton (Fig. 5, green and overlay panels in third and fourth rows from the top). In some of the cells, the HCPro BiFC-derived red filaments but not many of the red dots matched exactly the green MT fluorescence (Fig. 5 , overlay panels in third and fourth rows from the top; data
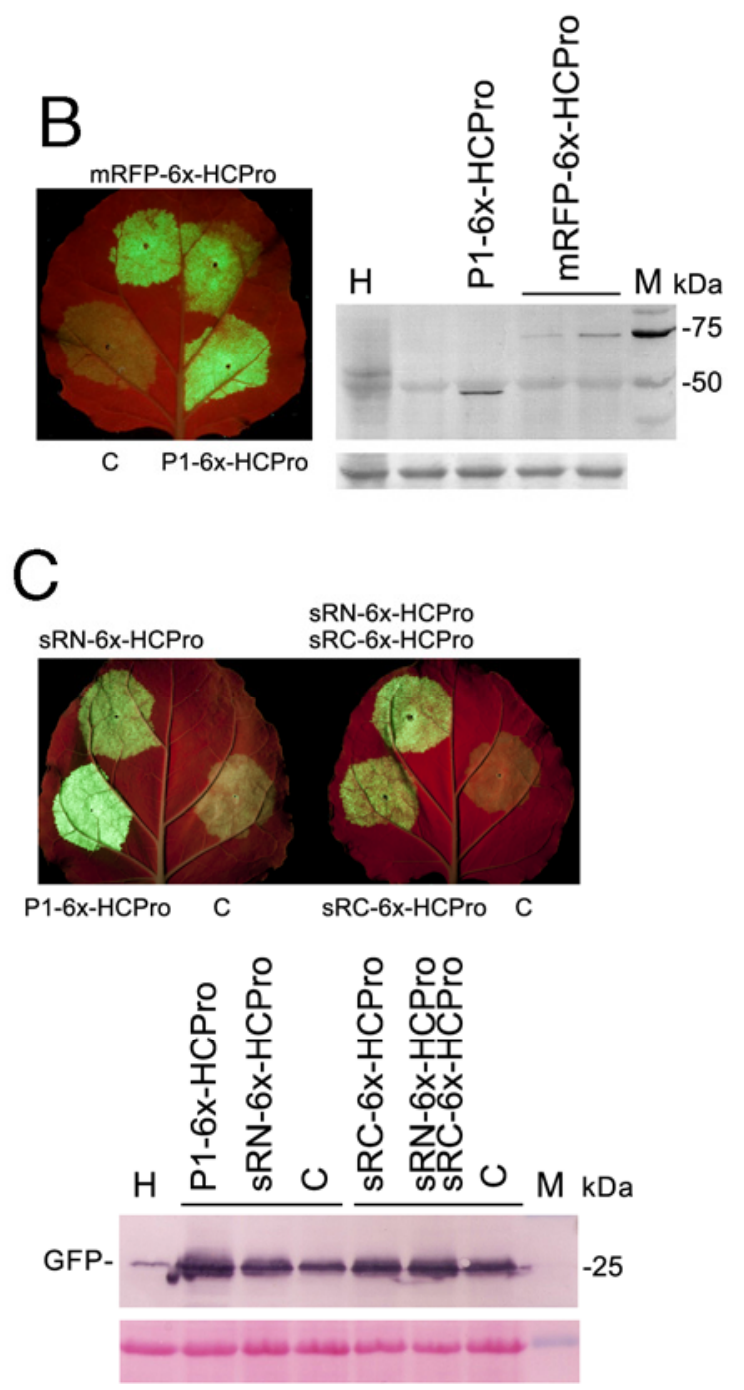

Fig. 2. Suppression of silencing in agropatch assays by N-terminally tagged HCPro constructs: a binary vector expressing a green fluorescent protein (GFP) reporter was agroinfiltrated together with the empty binary vector pROK2 (right side of leaves) or together with binary vectors expressing Potato virus $Y$ (PVY)-derived constructs. A, P1-6x-GFP-HCPro, 6x-GFP-HCPro, 6x-sYN-HCPro, 6x-sYC-HCPro or 6x-sYN-HCPro, plus 6x-sYC-HCPro (left side of upper left to bottom right leaves, respectively) and upper Western blot panel in which a polyclonal GFP antibody was used. The increase in GFP-derived fluorescence and on its accumulation was greatest in presence of P1-6x-HCPro and of 6x-sYN-HCPro, either alone or in combination with 6x-s YC-HCPro. By contrast, GFP tagging greatly reduced or abolished HCPro suppressor activity in this type of assay. Note that the serum also detects the GFP and split yellow fluorescent protein (sYFP)-tagged HCPro constructs. B, P1-6x-HCPro and mRFP-6x-HCPro (lower right side of leaf and upper patches, respectively) and right side Western blot panel using an anti 6xhistidine tag antibody. C, P1-6x-HCPro, sRN-6x-HCPro, sRC-6x-HCPro, and sRN-6x-HCPro plus sRC-6xHCPro (as labeled by the infiltrated patches). In contrast to the 6x-GFP tag, the monomeric red fluorescent protein (mRFP)-6x tag did not prevent suppressor activity, nor did the tags of the split mRFP parts (corresponding patches in leaves, and Western blot panel to GFP). In all Western blot panels, lane H shows a sample extracted from a healthy plant and lane $\mathrm{M}=$ prestained markers for molecular weight, indicated in kilodaltons (kDa). 
not shown). In addition, green fluorescence derived from the GFP-tagged $\alpha$-tubulin transgene product was also found in the large red irregular inclusions (Fig. 5, arrow in overlay panel in bottom row). Thus, large irregular HCPro inclusions contain tubulin.

In epidermal cells of red actin transgenic plants, green fluorescence derived from the $\mathrm{BiFC}$ of transiently expressed $6 \mathrm{x}$ sYN-HCPro + 6x-sYC-HCPro constructs did not colocalize with the red fluorescence associated with the plant actin filaments (Fig. 6, upper panels). Likewise, coexpression of 6x-sYNHCPro + 6x-s YC-HCPro with an m-cherry construct designed to target the Golgi stacks detected no sign of colocalization (Fig. 6, lower panels).

\section{Disruption of the MT network does not prevent HCPro suppression of silencing activity or its mediation of viral transmission by insect vectors.}

To test whether the integrity of the MT network would be required for HCPro biological activities that we could test in activity assays (suppression of silencing in patch assays or mediation of viral transmission by insect vectors), we disrupted the MT cytoskeleton using colchicine, as described by Wright and associates (2007). Three days after agroinjection of smRFP-HCPro constructs in Tua-GFP plants with colchicine in the infiltration buffer, green fluorescence derived from transgenic tubulin was distributed as dots or blobs instead of as filaments in epidermal cells, under stress conditions. By contrast, green fluorescence was distributed as filaments in the patches from the same plants injected with buffer lacking colchicine (Fig. 7A). In both cases, red fluorescence derived from BiFC of smRFP-tagged HCPros colocalized with the green tubulin, as either dots or filaments (Fig. 7A).

To test for the suppression of silencing activity of HCPro under undisrupted versus colchicine-disrupted MT cytoskeleton, we carried out a 3-day suppression of silencing patch assay using a free GFP reporter and suppressor P1-6x-HCPro, as well as CMV $2 b$ and TBSV P19. The test was performed both in nontransgenic and in Tua-GFP-transgenic $N$. benthamiana plants. In all cases, suppression of the partial silencing of the transiently expressed GFP reporter was comparable in the presence and in the absence of colchicine (Fig. 7B, upper versus lower patches in left side of leaves; compare GFP fluorescence derived from the reporter under UV light). This happened even if the amount of colchicine injected $(5 \mu \mathrm{M})$ was 10 times that required for efficient disruption of the MT (Fig. 7B, lower panel). Thus, integrity of the MT cytoskeleton is not required for suppressor of silencing activity in patch assays.

To test the potential requirement of intact MT cytoskeleton for HCPro to mediate aphid transmission, we injected aphidtransmissible, PVY-infected $N$. benthamiana leaves with either colchicine or buffer without this substance and, 3 days after injection, we carried out viral transmission tests with aphids. Transmission efficiencies were similar in both cases, at $100 \%$. Furthermore, we carried out one experiment in which we injected $5 \mu \mathrm{M}$ colchicine, 10 times the amount required to disrupt the cytoskeleton, and the results were similar (Fig. 7C).

\section{DISCUSSION}

Members of the genus Potyvirus are among the most successful and economically relevant plant viruses to agriculture, despite their translation strategy leading to the expression of almost all their protein factors in equimolar amounts. Because it appears that not all these proteins would be required in similar amounts at any given time during the viral infection cycle, this strategy would not seem efficient, unless turnover of the different viral products and their accumulation in specific structures for storage, removal, or degradation within the cell at different times or under different environmental conditions was closely integrated and programmed. In this regard, several potyvirus proteins are known to form inclusion structures in

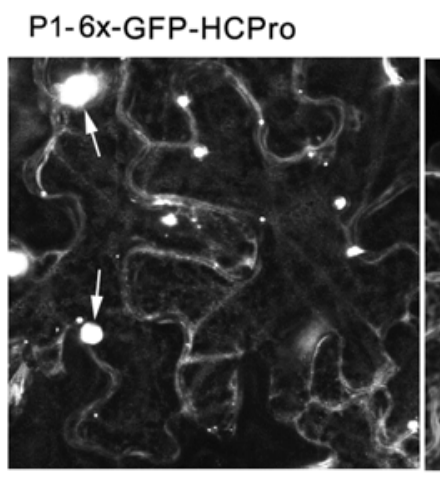
mRFP-6x-HCPro

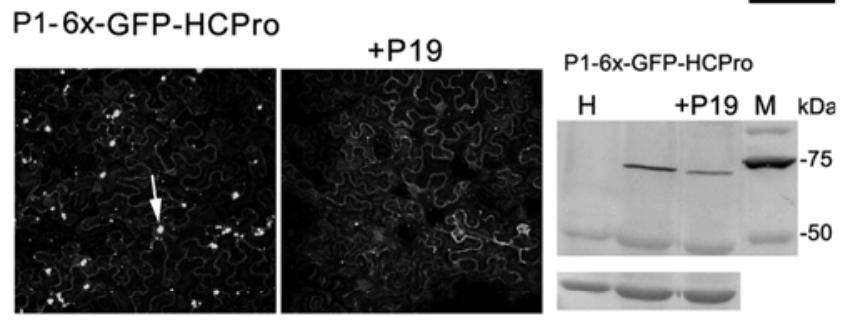

\section{6x-sYN-HCPro} 6x-sYC-HCPro
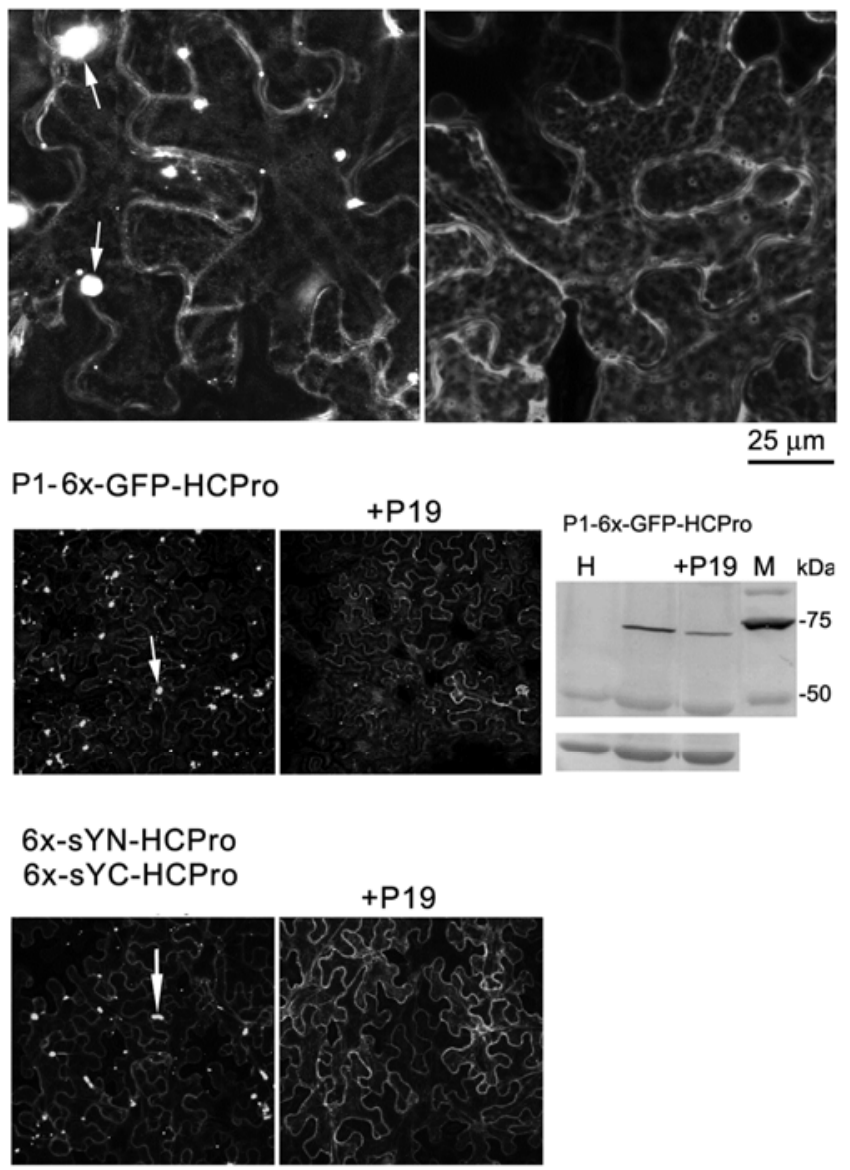

$25 \mu \mathrm{m}$

sRN-6x-HCPro sRC-6x-HCPro
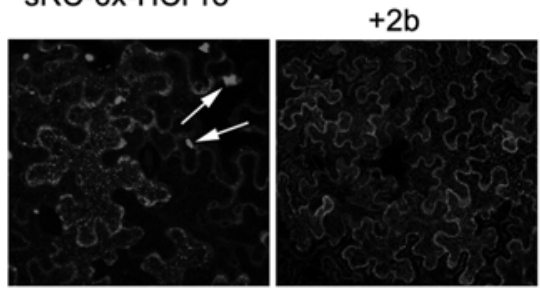

$50 \mu \mathrm{m}$

Fig. 3. Visualization of the distribution of fluorescence derived from green fluorescent protein (GFP)-tagged HCPro (construct P1-6x-GFP-HCPro) from monomeric red fluorescent protein (mRFP)-tagged HCPro (construct mRFP-6x-HCPro), or from the bimolecular fluorescence complementations (BiFC) between the two split yellow fluorescent protein (sYFP)-tagged HCPros (constructs 6x-sYN-HCPor and 6x-sYC-HCPro) or the two split monomeric red fluorescent protein (smRFP)-tagged HCPros (constructs sRN-6x-HCPro and sRC-6x-HCPro) transiently expressed by agroinfiltration in fields of epidermal cells of Nicotiana benthamiana leaves. Fluorescence derived from the GFP and mRFP tags is found throughout what appears as the cytoplasm; in particular, in large irregular inclusions (arrows in panels) that were absent in the case of construct mRFP-6x-HCPro (upper left and right panels, respectively). Addition of heterologous viral suppressors of silencing such as the tombusviral P19 or cucumoviral $2 \mathrm{~b}$ protein had the effect of making these inclusions smaller, without increasing the steady-state levels of HCPro, as indicated in the Western blot panel for construct P1-6xGFP-HCPro (third lane, P19 added versus second lane, empty vector added) or for the BiFC pairs 6x-sYN-HCPro + 6x-sYC-HCPro and sRN-6x-HCPro + sRC-6x-HCPro (third and fourth rows of panels from the top, respectively). Size bars are indicated in the bottom right corner. 
different subcellular compartments such as, among others, the nuclear inclusion proteins NIa and NIb within the nucleus, the characteristic plasmodesmata (PD)-associated pinwheels formed by the cylindrical inclusion (CI) helicase protein in the cytoplasm (Sorel et al. 2014), or the cytoplasm-scattered amorphous inclusions of HCPro (Baunoch et al. 1990).

Despite extensive literature, our overall view of the turnover of potyviral proteins or the structures they form and their biological significance is rather poor. That is, are these structures functional sites or only places to remove excess protein? Are these structures reversible or do they contain host factors such as proteins or nucleic acids that may interfere with the progress of the infection or, alternatively, that may need recruiting for use at some further step of the viral infection? How do all of these proteins travel there from the translation sites? In this regard, research into the CI helicase has shown how this protein, in addition to its enzymatic role in replication, is involved in the translation of the vesicle-associated viral replication factories from the ER toward the protoplast membranes via actin filaments (Wei et al. 2010a), while it also translocates via the ER-Golgi secretory pathway toward the PDs, where it anchors through its interaction with viral P3N-PIPO and is involved somehow in the local movement of the virus (Wei et al. 2010b).

In contrast to the CI protein, we have a less integrated view of the subcellular dynamics of HCPro interactions, translocation pathways, accumulation, and their relation to its several functions. HCPro is a factor important to processes such as viral replication or local movement but two roles make it essential to the virus cycle: as a strong suppressor of antiviral gene silencing and as a helper factor in the horizontal transmission of the virus by vectors. Microscopy observational data from previous works with different potyviral HCPros have individually linked it to the cytoplasm, distributing diffusely or forming inclusions (Baunoch et al. 2002; Mlothswa et al. 2002; Sahana et al. 2012, 2014; Zheng et al. 2011; Zillian and Maiss 2011). It has also been suggested that it may affect ER structure (Zheng et al. 2011), and it has been found to bind in $\mathrm{Y} 2 \mathrm{H}$ and in vivo (BiFC) to a protein (HIP2) associated with the cellular
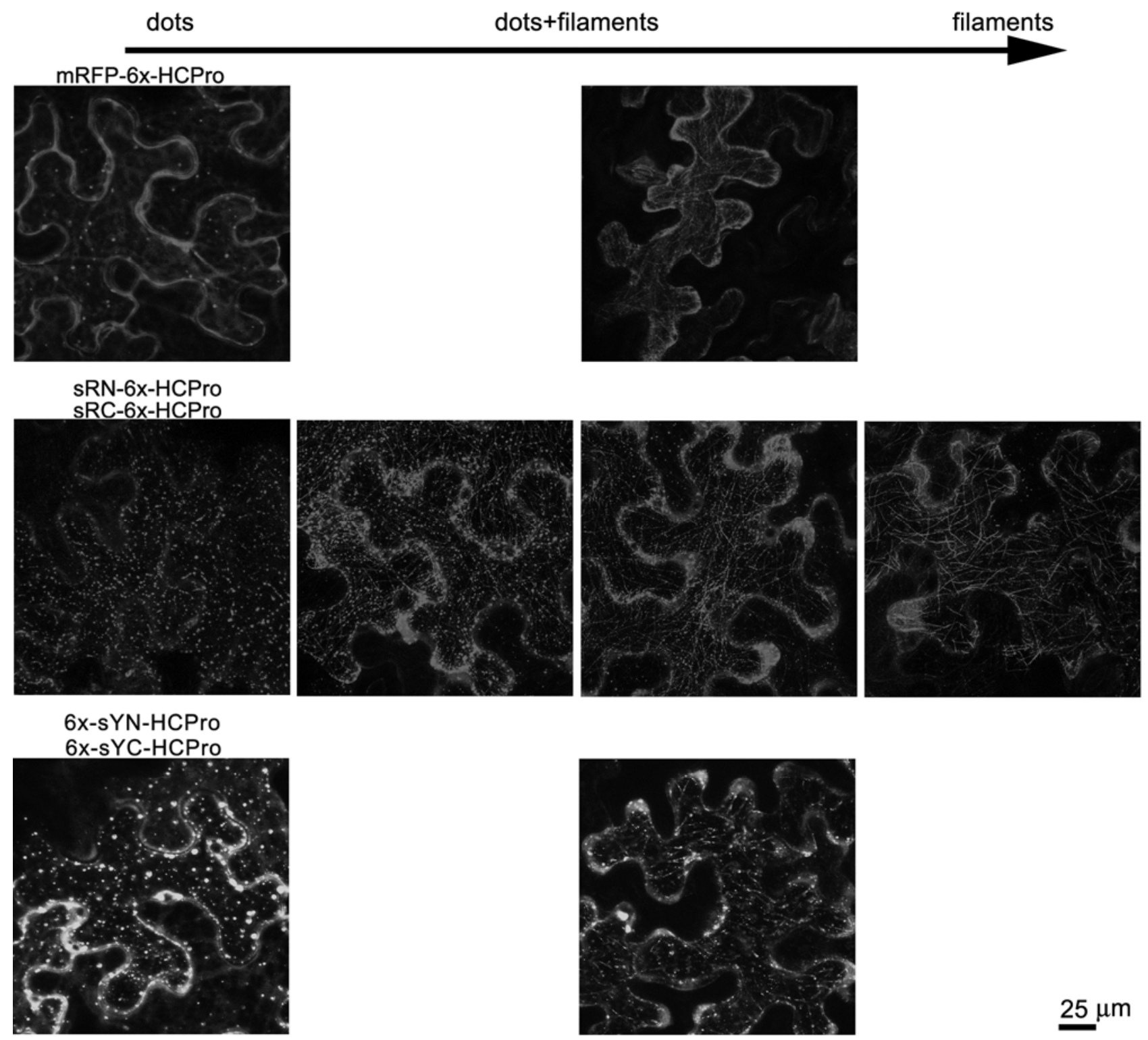

Fig. 4, Close-up view at high magnification within the cytoplasm of individual epidermal cells in which fluorescence distributes as dots of similar size arranged in a regular, reticulate pattern (leftmost panels), as combinations of fluorescent dots and connecting filaments, or mainly as filaments (central and rightmost panels, respectively). The horizontal arrow above the set of panels indicates the increase in filament- versus dot-associated fluorescence and does not suggest any direction to protein traffic. Size bars for panels are indicated in the bottom right corner. 
sRN-6x-HCPro

SRC-6x-HCPro in transgenic plants expressing green fluorescing cortical endoplasmic reticulum
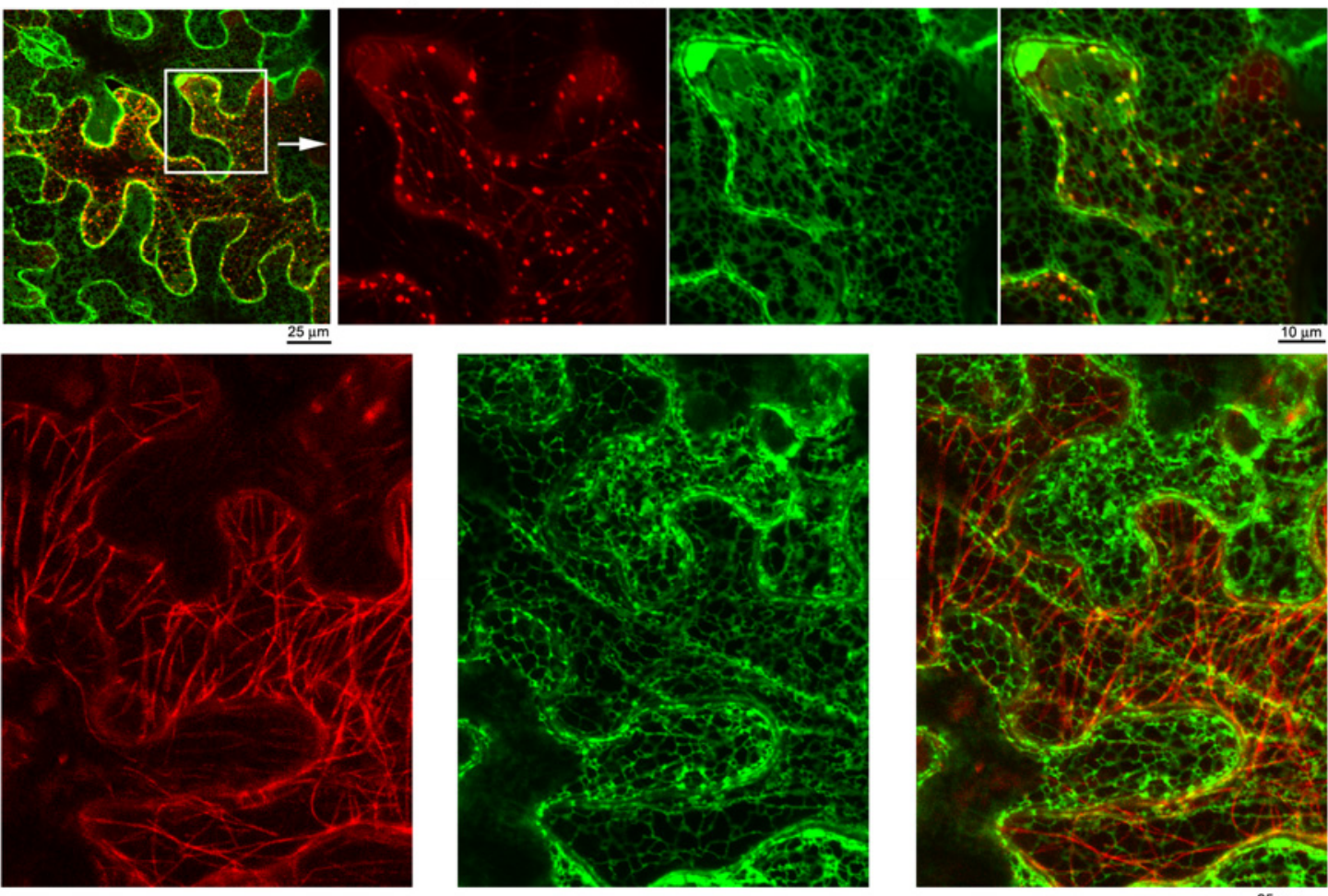

\section{sRN-6x-HCPro}

SRC-6x-HCPro in transgenic plants expressing green fluorescing $\alpha$-tubulin
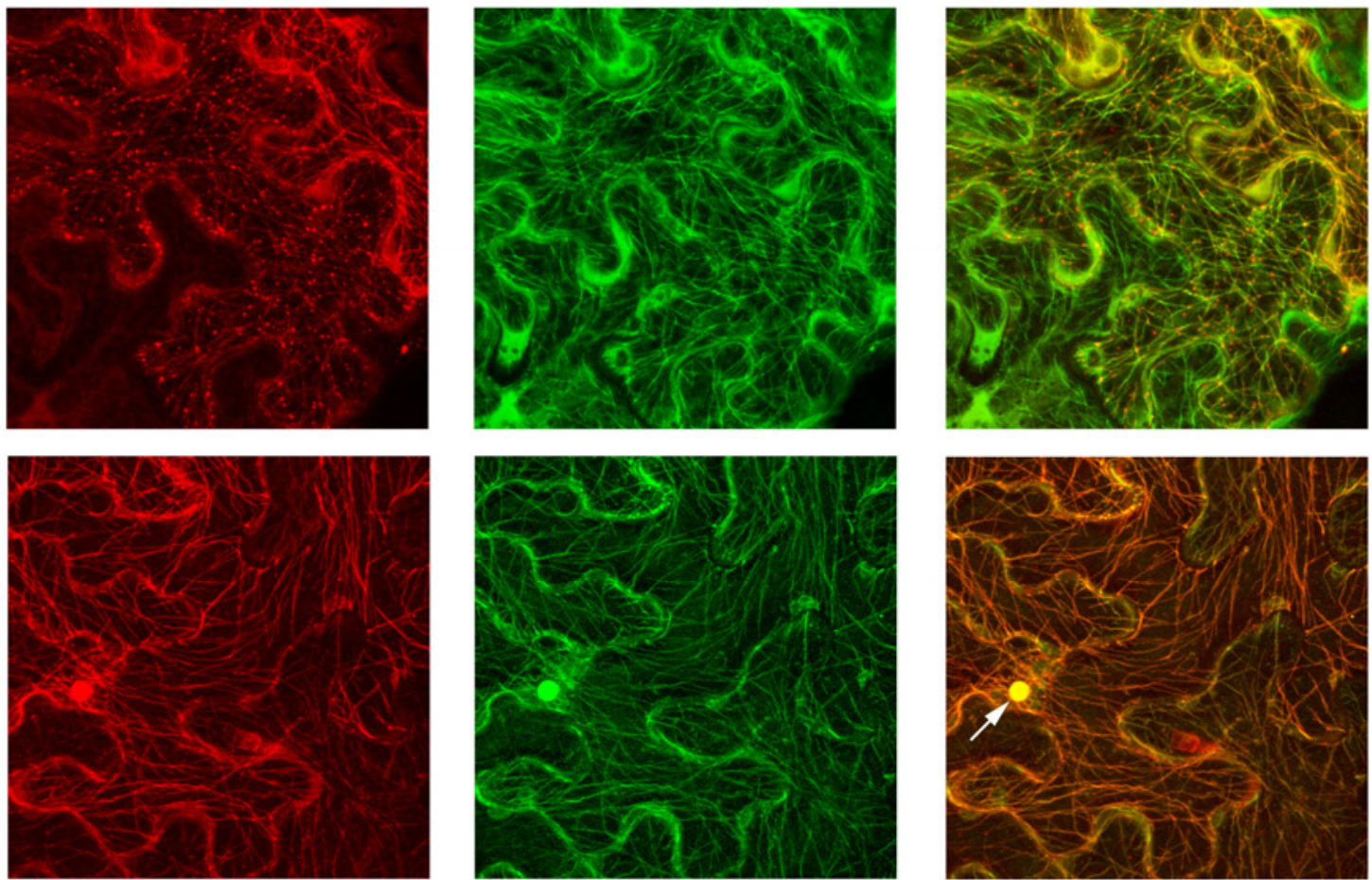

GREEN

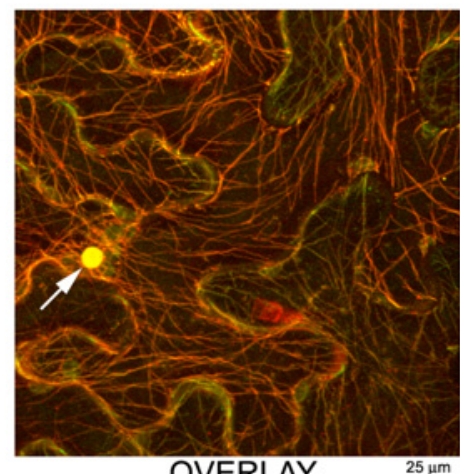

OVERLAY

Fig. 5. Visualization of the subcellular distribution of fluorescence derived from the bimolecular fluorescence complementation (BiFC) between the two split monomeric red fluorescent protein (smRFP)-tagged HCPros (constructs sRN-6x-HCPro and sRC-6x-HCPro) transiently expressed by agroinfiltration in epidermal cells of transgenic Nicotiana benthamiana leaves that show their cortical endoplasmic reticulum (ER) fluorescing green (Line 16c) (Ruíz et al. 1998) or their microtubule (MT) cytoskeleton fluorescing green by expressing green fluorescent protein (GFP)-tagged $\alpha$-tubulin (Tua-GFP plants) (Gillespie et al. 2002). Panels show either monochrome green (from ER or MT in transgenic plants) or red (from BiFC HCPro transiently expressed constructs) fluorescence, or overlays of both colors for colocalization studies. HCPro fluorescence either as dots (upper top left panel and enlarged area) or as filaments (upper middle panels) did not colocalize with that from the ER (middle panels). However, HCPro fluorescent dots appeared anchored to the ER scaffold (upper top panels). By contrast, HCPro distribution as filaments matched perfectly that of the MT cytoskeleton but not when distributing as dots (lower panels). Note that, interestingly, tubulin-derived green fluorescence did colocalize with that from HCPro in large irregular inclusions (arrow in lower panels). Size bars for corresponding panels appear at the bottom right corners. 
MT, an interaction that is important to virus infection (Guo et al. 2003; Haikonen et al. 2013a and b). Our present work's contribution to PVY HCPro subcellular whereabouts and dynamics in vivo uses fluorescently tagged constructs whose biological activities as suppressors have been assessed (Fig. 2). Although several studies have been published involving tagged HCPros for in vivo localization or protein-protein interaction studies using confocal or epifluorescent microscopy or $\mathrm{Y} 2 \mathrm{H}$ assays, surprisingly little has been done to assess the effect of these tags and modifications on the biological activities of the tagged constructs in planta. To our knowledge, ours is the first assessment of suppressor activity of the different tagged HCPros studied, using agropatch assays.

With our N-terminal-tagged constructs, we could visualize fluorescence derived from both single HCPro molecules and the interacting homodimers that carried complementary BiFC tags. Our work was carried out in a virus-free system and, thus, it does not replicate the infected cell environment. As a transient expression system, there was no infection front or infected rearguard to distinguish, either. Even so, our results were remarkably in agreement with previous published observations, and data from the different constructs we have used were consistent overall. PVY HCPro showed a diffuse presence throughout the cytoplasm, as well as large irregular inclusions (Fig. 3). These inclusions could be the equivalent of amorphous inclusions observed by inmunomicroscopy (Baunoch et al. 1990). We did not observe them for construct mRFP-6xHCPro but this might be because the tag prevented their formation, the same way that the GFP tag interfered with the suppressor activity of HCPro. However, because construct mRFP6x-HCPro displayed good suppressor activity in agropatch assays, the irregular inclusions are seemingly not required for this function. Two features of these large inclusions can be underlined. The first is that, in the presence of heterologous suppressors of gene silencing such as P19 or 2b protein, both their number and size diminish drastically (Fig. 3). We do not know the reason for this, but we could speculate that a host factor, either protein or nucleic acid, required for the formation of these inclusions is prevented from doing so by the heterologous suppressors. In any event, it shows that inclusion formation (their number and size) is dependent on factors external to HCPro itself and suggests that they may not be as irreversible or permanent as thought. The second observation is that, in Tua-GFP transgenic plants, these large inclusions contain GFP-tagged $\alpha$-tubulin (Fig. 5). This suggests that these inclusions could be linked to the MT cytoskeleton. In this regard, it appears relevant to mention that caulimovirus aphid transmission helper factor P2 (the equivalent to potyviral HCPro as and aphid helper transmission factor) accumulates in a tubulin- and virion-containing large inclusion that, in response to insect probing, disperses throughout the cell cytoplasm using the MT cytoskeleton, facilitating transmission (Martiniére et al. 2013).

We also found two additional characteristic patterns of subcellular localization of PVY HCPro. One was a not previously described pattern of small dots of similar size, distributed regularly throughout the cytoplasm, which in 16c ER-fluorescent transgenic plants appeared clearly associated or anchored to the ER (Fig. 5). ER-linked structures that bear visual resemblance to these have been reported for other virus proteins such as Tobacco mosaic virus movement protein (Gillespie et al. 2002) which, on its way to the proteasome for degradation, also associates with MT or, in the case of potyviruses, the $6 \mathrm{~K}$ protein (Wei and Wang 2008), which would be related to the genesis of sites of viral replication-translation. In our virus-

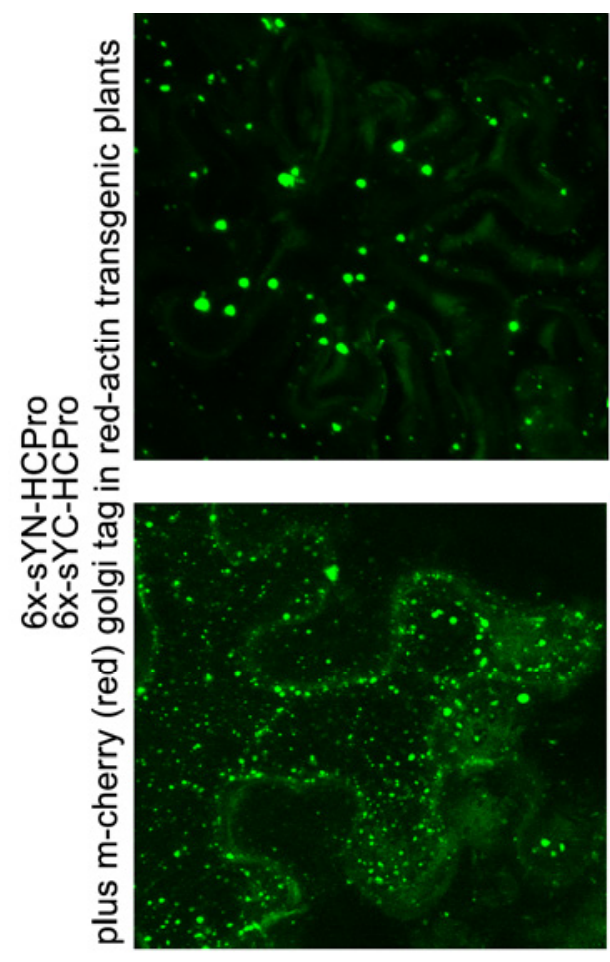

GREEN
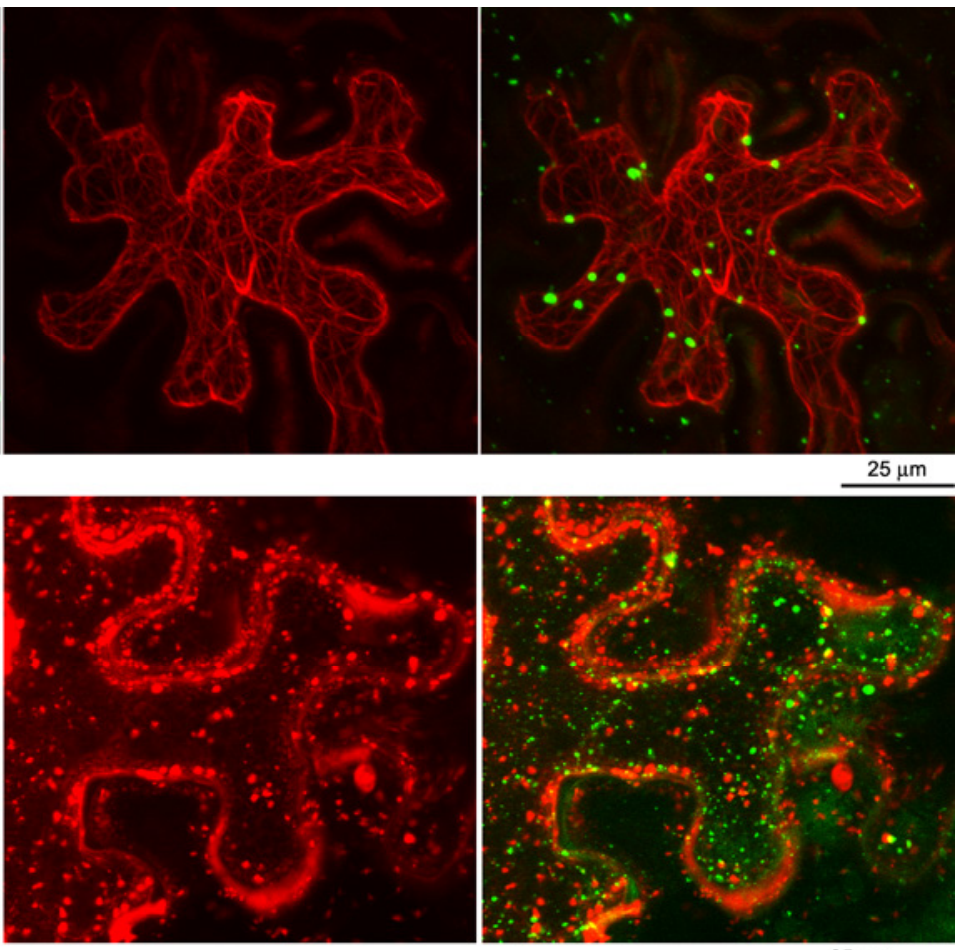

RED

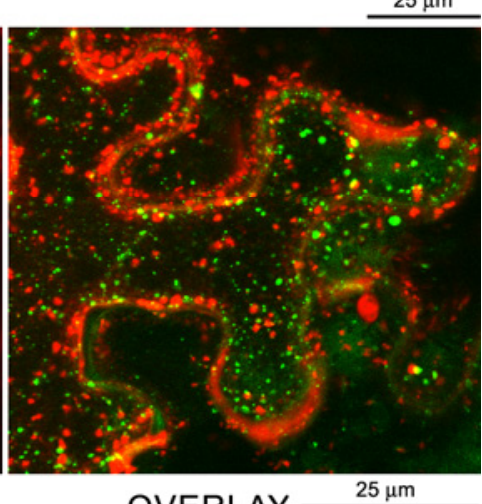

OVERLAY $25 \mu \mathrm{m}$

Fig. 6. Visualization of the subcellular distribution of fluorescence derived from the bimolecular fluorescence complementation (BiFC) between the two split yellow fluorescent protein (sYFP)-tagged HCPros (constructs 6x-sYN-HCPro and 6x-sYC-HCPro) transiently expressed in epidermal cells of transgenic Nicotiana benthamiana leaves that constitutively express a Lifeact TagRFP fusion targeting actin in the upper row of panels, or together with a binary vector that expresses mCherry protein with a targeting signal to Golgi stacks (Nelson et al. 2007) in the lower row of panels. Panels show either monochrome green (from BiFC-derived HCPro fluorescence) or red (from red actin filaments or from Golgi) fluorescence, or overlays for colocalization studies. No colocalization between green and red fluorescence was observed in both cases. Size bars for corresponding panels appear at the bottom right corners. 

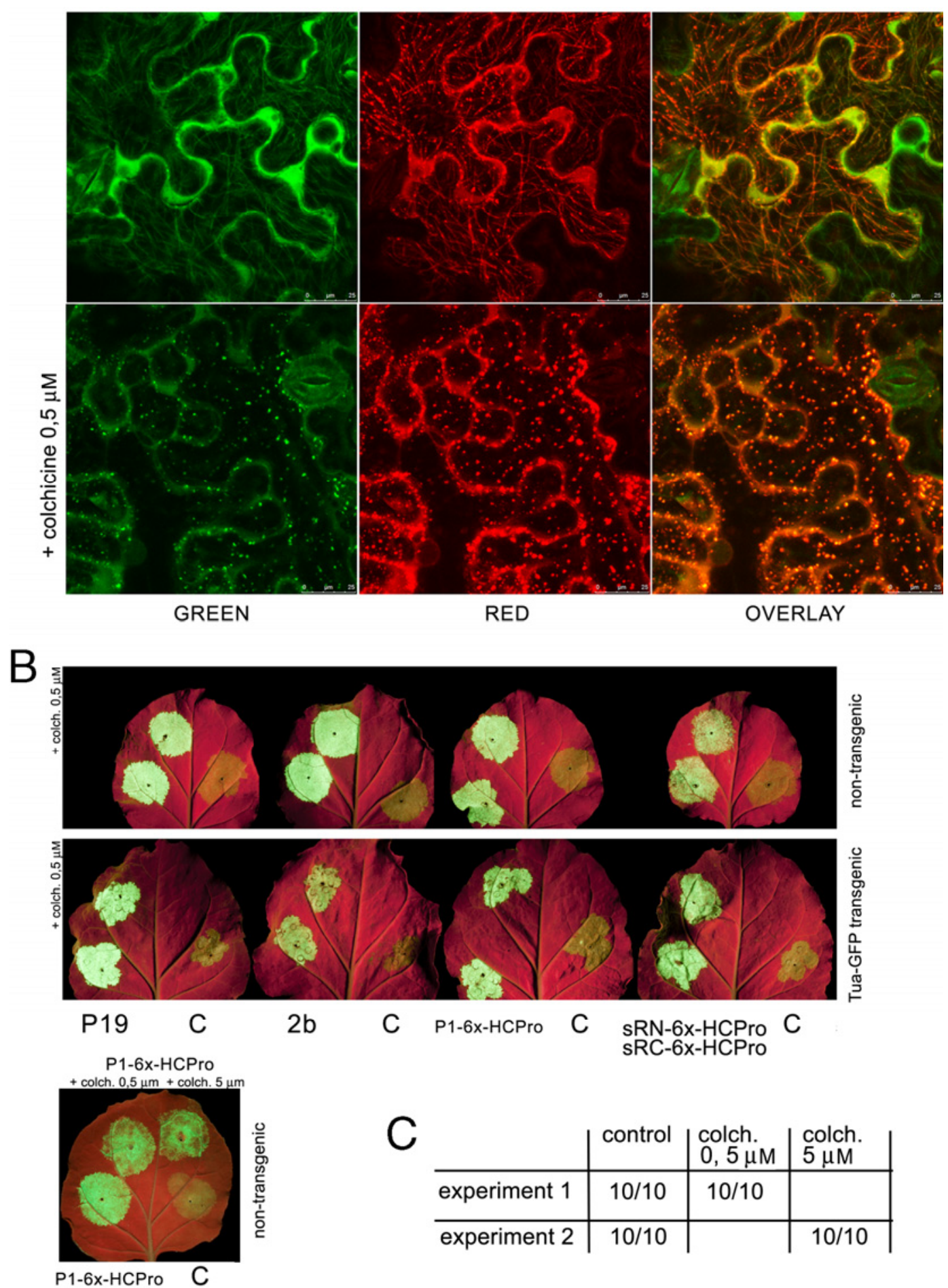

Fig. 7. Disruption of the microtubule (MT) cytoskeleton and its effect on HCPro suppression of silencing activity and on its mediation of virus transmission by aphids. A, Visualization of the subcellular distribution of fluorescence derived from the bimolecular fluorescence complementation (BiFC) between the two split monomeric red fluorescent protein (smRFP)-tagged HCPros (constructs sRN-6x-HCPro and sRC-6x-HCPro) transiently expressed by agroinfiltration in epidermal cells of transgenic Nicotiana benthamiana leaves that express green fluorescent protein (GFP)-tagged $\alpha$-tubulin (Tua-GFP plants) (Gillespie et al. 2002). Agrobacteria was infiltrated in the absence or presence in the agroinfiltration solution of colchicine at $0.5 \mu \mathrm{M}$ (upper and lower rows, respectively). Colchicine had the effect of disrupting the MT cytoskeleton into dots (lower green panel). However, red fluorescence from BiFC of HCPro constructs still colocalized with that of the tubulin in those dots. B, Suppression of the silencing in agropatch assays of a binary vector expressing a green fluorescent protein (GFP) reporter agroinfiltrated together with the empty binary vector pROK2 (right side of leaves) or together with binary vectors expressing tombusviral P19, Cucumber mosaic virus $2 \mathrm{~b}$ protein, Potato virus $Y$ (PVY)-derived P1-6x-HCPro construct or the combined sRN-6x-HCPro plus sRC-6x-HCPro constructs (left side of leaves) in either the absence or presence of $0.5 \mu \mathrm{M}$ colchicine (lower versus upper patches in left side of leaves): suppressor effects on the transient levels of fluorescence derived from the reporter did not appear affected adversely by the colchicine. C, Transmission by aphids of PVY from systemically infected $N$. benthamiana leaves. Leaves had been infiltrated 3 days prior to the transmission experiment with water (as control) or with colchicine $(0.5 \mu \mathrm{M}$ in experiment 1 and $5 \mu \mathrm{M}$ in experiment 2). Five aphids were used per receptor plant. Transmission was 10 out of 10 plants in all cases. 
free system, PVY HCPro localized to these structures without need of interaction with another viral factor. The second pattern showed HCPro-derived fluorescence as filaments which, in Tua-GFP plants, overlapped the fluorescent MT (Figs. 5 and 7). Interestingly, the ER-associated dots of HCPro were also connected to the MT cytoskeleton (Fig. 5, third row of images). Our results are in agreement with observations by Haikonen and associates (2013a and b) that showed, through $\mathrm{Y} 2 \mathrm{H}$, that HCPro from both PVY and PVA bound to the MT-associated factor HIP2. Visualization by BiFC of the PVA HCPro/HIP2 interacting pair showed a filamentous distribution (Haikonen et al. 2013b) similar to our colocalization of fluorescence from HCPro or its homodimers with that from transgenic fluorescent tubulin (Figs. 5 and 7A). Therefore, PVY HCPro BiFC homodimers may colocalize with the MT through this same host factor.

In addition to both patterns, we found numerous intermediate forms that showed both HCPro fluorescence in ER-linked dots as well as MT-linked filaments which, in our opinion, could be better explained if there was a dynamic connection between both patterns (Fig. 4). We do not know the direction of the protein transport (from dots or the diffuse cytoplasm toward MT or vice-versa) or whether it is bi- or multidirectional. An important feature of the MT-associated pattern is that it appears mainly but not exclusively after the live tissue has been subjected to stresses. Haikonen and associates (2013b) found the filamentous pattern in epidermal cells overexpressing both split YFP-tagged PVA HCPro-HIP2 BiFC constructs but not in cells expressing fluorescent HCPro, in which, instead, fluorescence spread diffusely throughout the cytoplasm. They suggest that low cellular levels of endogenous HIP2 could be responsible for the absence of a tubular pattern in the latter case. However, in our results, relocation of PVY HCPro toward the MT was extensive and took place within minutes of the added stress in those cells affected (Figs 4, 5, and 7) and, if mediated by HIP2, it would have to necessarily imply that the latter was not a limiting factor. Alternatively, HCPro coating of MT could also take place through another, HIP2-independent route. What physical process makes HCPro relocate to the MT in response to the stress? We could speculate that a host factor is released from a place where it has no contact with HCPro, or that it suffers some structural alteration that allows it to take place.

We finally tested whether the integrity of the MT cytoskeleton was required for HCPro suppressor of silencing activity or for its mediation of viral transmission by aphids. For that, we disrupted the cytoskeleton by providing colchicine as described (Wright et al. 2007). MT disruption in Tua-GFP plants did not prevent colocalization of PVY HCPro with green tubulin in dot-like structures (Fig. 7A), indicating that colocalization did not require an MT tubular architecture. In agropatch assays, we could not find a negative effect of MT disruption on the HCPro suppressor activity on the transient expression of a GFP reporter (Fig. 7B) or on the viral transmission by aphids from a PVY-infected plant (Fig. 7C); in both cases, even at doses that were 10 times higher than those needed to completely disrupt the MT. Therefore, despite the HCPro-HIP2 interaction being important to PVA infectivity (Haikonen et al. $2013 \mathrm{~b}$ ), in our experimental conditions, suppression of silencing or mediation of viral transmission by vectors functions did not require the integrity of the MT network. These results were unexpected and leave open the quest for a biological role of the binding of HCPro to MT under stress and its transit through that network for further research.

In conclusion, we have shown that, in addition to a diffuse presence throughout the cytoplasm, PVY HCPro displays several distinct subcellular localization patterns which can be influenced by the cellular environment: as large irregular, tubulin-containing inclusions; as novel, dot-sized ER- and MTassociated structures; and, finally, coating the MT in response to stresses. We also show that there is a continuum between the two latter forms that support the existence of HCPro transport between both. By contrast, in a system free from other virus components, we found no evidence of HCPro trafficking through the secretory pathway or following actin filaments. Despite its association with MT, the integrity of this tubular cytoskeleton was not necessary for HCPro suppression of silencing activity in agropatch assays or for its mediation of PVY transmission by aphids from infected plants.

\section{MATERIALS AND METHODS}

\section{Plasmid constructs.}

For transient expression in plants, proteins were cloned into the $35 \mathrm{~S}$ promoter-polylinker-Nos terminator T-DNA cassette of pROK2-based binary vectors. Cloning of construct P1HCPro with the P1HCPro sequence from PVY has already been described (Canto et al. 2002). Cloning of construct P16x-HCPro has also been described, as was the determination that it has suppressor activity in agropatch assays similar to that of the native protein (Tena et al. 2013). To generate constructs P1-HCPro-mRFP and P1-HCPro-GFP, the P1-HCPro sequence without a terminator codon was amplified by polymerase chain reaction (PCR) with appropriate oligonucleotides, digested with NheI, and cloned into XbaI-linearized pROK2, in frame with either the $m R F P$ or GFP genes that had previously been inserted at the $\mathrm{XbaI}-\mathrm{SacI}$ sites of the pROK2 polylinker. For the generation of GFP- and sYFP-tagged constructs, HCPro sequences were amplified by PCR using appropriate oligonucleotides and cloned into pROK2 harboring GFP or pROK harboring sequences corresponding to sYFP $\mathrm{N}$ or $\mathrm{C}$ terminal halves already described (González et al. 2010) at the $X b a \mathrm{I}-B a m \mathrm{HI}$ sites of their respective polylinkers, to generate intermediate constructs GFP-HCPro, sYN-HCPro, and sYCHCPro. To add an N-terminal tag of methionine plus six histidines (Met-6xHis; ATG-CAT-CAC-CAT-CAC-CAT-CAC) to these three constructs as well as to construct HCPro, the sequences corresponding to the tags, if present, plus the first $5^{\prime}$ 330 nucleotides of the HCPro sequence were amplified by PCR with four appropriate $5^{\prime}$ oligonucleotides that contained the Met-6xHis sequence and a common $3^{\prime}$ oligonucleotide (nucleotides 319 to 339). The four PCR fragments were digested with NheI and XhoI (a unique site present at nucleotide 330 of the HCPro sequence) and inserted into the above-mentioned constructs and linearized with $\mathrm{XbaI}-\mathrm{XhoI}$ in place of the original sequences, thus generating constructs $6 \mathrm{x}-\mathrm{HCPro}, 6 \mathrm{x}-\mathrm{GFP}$ HCPro, 6x-sYN-HCPro, and 6x-sYC-HCPro, respectively. To insert the Met-6xHis sequence between the $P 1$ and HCPro sequence or between the $P 1$ and GFP-HCPro sequences, the $P 1$ sequence was amplified by PCR with an appropriate $5^{\prime}$ oligonucleotide and a $3^{\prime}$ oligonucleotide complementary to the end of the $P l$ sequence plus a serine codon and an NheI site (CAGTTT[Pl]AGC[serine]GCTAGC[NheI site; prolineserine]). On the other hand, two sequences from constructs $6 \mathrm{x}$ HCPro and 6x-GFP-HCPro were amplified by PCR using a 5' oligonucleotide containing the Met-6xHis tag sequence with an added NheI site upstream, and an appropriate $3^{\prime}$ oligonucleotide. These two PCR fragments were cleaned, digested with NheI, and ligated in vitro to the NheI-digested P1 PCR fragment. The ligation products were then used to amplify two PCR fusion fragments using the $\mathrm{P} 15^{\prime}$ oligonucleotide and the $3^{\prime}$ oligonucleotide at the HCPro sequence (nucleotides 319 to 339). The fusion fragments thus obtained contained a P1-(Ser-ProSer-Met-6xHis-Met)-GFP or HCPro sequence at the fusion 
sites. The two fusion PCR products were digested with BamHI and XhoI and cloned into equally linearized construct P1HCPro, generating constructs P1-6x-HCPro and P1-6x-GFPHCPro, respectively. For large-scale purifications of P1-6xHCPro and of P1-6x-GFP-HCPro from plants, both sequences were amplified by PCR with appropriate oligonucleotides and cloned into a binary construct expressing an infectious Potato virus $X$ (PVX) vector (construct pgR 107) (Lu et al. 2003), linearized with ClaI and SmaI. To obtain HCPro constructs tagged at their $\mathrm{N}$-termini with the mRFP 1 or its $\mathrm{N}$-terminal and C-terminal splits for BiFC, plus 6 histidines, $m R F P$ or its $5^{\prime}$ and $3^{\prime}$ split part sequences were amplified by PCR with appropriate oligos and cloned into XbaI- and BamHI-linearized pROK2 to create intermediate constructs pROK2-smRFP1, pROK2-split mRFPN (encoding the protein $168 \mathrm{~N}$-terminus amino acids), and construct pROK2-split mRFPC (encoding a methionine plus the $58 \mathrm{C}$-terminus amino acids), respectively, following Zillian and Maiss (2007). On the other hand, the HCPro sequence was amplified by PCR from construct P1-6xHCPro using a 5 'oligo that contained a BamHI site followed by 6 histidines and a $3^{\prime}$ oligo complementary to the $3^{\prime}$ end of HCPro coding sequence, followed by a stop codon and a KpnI site. This fragment was cloned into constructs pROK2-smRFP1, pROK2-split mRFPN, and pROK2-split mRFPC and linearized with BamHI and $K p n$ I to generate binary constructs mRFP-6xHCPro, sRFPN-6x-HCPro, and sRFPC-6x-HCPro, respectively. All constructs were fully sequenced prior to experimental use. The $2 b$ sequence from CMV var. Fny was amplified by the PCR with appropriate oligos and cloned into BamHI- and SacI-linearized constructs pROK2-split mRFPN and pROK2split mRFPC to create constructs sRFPN-2b and sRFPC-2b, respectively, which express the CMV $2 b$ suppressor fused to the split parts of the mRFP.

\section{Plant material.}

This work used $N$. benthamiana plants, either wild-type or transgenic, for the constitutive expression of GFP targeting the cortical ER (line 16c) (Ruíz et al. 1998), of GFP fused to $A$. thaliana $\alpha$-tubulin (Tua-GFP) (Gillespie et al. 2002), or a Lifeact TagRFP fusion targeting actin filaments. Lifeact TagRFP plasmid was made by primer extension PCR, as described by Berepiki and associates (2010). Gateway adapters were added by PCR with primers 5'-GGGGACAAGTTTGTACAAAAAA GCAGGCTGCATGGGTGTCGCAGATTTGATCAAG-3' and 5'-GGGGACCACTTTGTACAAGAAAGCTGGGTCTTACT TGTACAGCTCGTCCATGCC-3', and the resulting PCR product was recombined into pDONR207 (LifeTechnologies). After sequence verification, Lifeact TagRFP was recombined into pGRAB.TEVL (SC1046), a derivative of pGreen0229 containing a $35 \mathrm{~S}$ promoter and a TEV leader sequence upstream of the Gateway cassette. pGRAB.TEVL Lifeact TagRFP plasmids were mobilized into Agrobacterium strain AGL1+psoup and used to transform $N$. benthamiana leaf segments as described by Horsch and associates (1985), with Basta-resistant plants being regenerated and screened for expression by fluorescence microscopy.

\section{Expression of proteins in plants from binary vectors, and purification of HCPro and PVY.}

For transient expression assays, binary vectors were transferred to the same batch of electrocompetent Agrobacterium tumefaciens $\mathrm{C} 58 \mathrm{C} 1$ derived from a single colony, to prevent bacterial variability. Cultures were grown to exponential phase in Luria-Bertani medium with antibiotics at $28^{\circ} \mathrm{C}$. For infiltration, each bacterial culture harboring a different T-DNA was diluted to a final optical density of 0.2 at $600 \mathrm{~nm}$. Different cultures harboring different T-DNAs were then combined and infiltration of the mixtures was performed on fully expanded leaves of nonflowering $N$. benthamiana plants using a syringe, as described (Canto et al. 2002). Large-scale purifications of P1-6x-HCPro and of P1-6x-GFP-HCPro were performed from plants infected with constructs PVX-P1-6x-HCPro and PVXP1-6x-GFP-HCPro, as described (Tena et al. 2013). A purified virion prep from an aphid-transmissible PVY isolate (Scottish ordinary variety PVY-O; Scottish Agricultural Science Agency), from which the P1-HCPro sequence used in this study derived (Canto et al. 2002), was obtained from systemically infected $N$. benthamiana plants as described, omitting the sucrose gradient final step (Moghal and Francki 1976).

\section{Local suppression of silencing in agroinfiltration patch assays.}

A free $G F P$ reporter gene expressed from a binary vector under the control of the $35 \mathrm{~S}$ promoter was expressed transiently in an $N$. benthamiana leaf, either co-infiltrated with the empty binary vector $\mathrm{pROK} 2$ or with another vector expressing a protein to be tested for suppression of silencing activity. To monitor the effect of the second protein on the levels of fluorescence derived from the transiently expressed free enhanced GFP, leaves were illuminated at 3 to 6 days postinoculation (dpi) with a Blak Ray long-wave UV lamp (UVP, Upland, CA, U.S.A.) and photographed as previously described (González et al. 2010).

\section{Imaging of fluorescence from tagged proteins} in live cells and tissues, and chemical treatments.

Epidermal cells in $N$. benthamiana-infiltrated leaves were monitored live for fluorescence derived from GFP-, mRFP-, smRFP-, mCherry-, or sYFP-tagged proteins transiently expressed at 3 to 5 dpi. Imaging was conducted with Leica SP2 and SP5 (Leica Microsystems GmbH, Heidelberg, Germany) confocal laser-scanning microscopes and software, using fresh leaf tissue and $\times 63$ magnification oil immersion objectives. Excitation and emission settings in nanometers were the following: GFP (488 and 500 to 530); BiFC sYFP (514 and 530 to 550); and mRFP, BiFC smRFP, and mCherry (561 and 575 to 640). To visualize the cortical ER, actin filaments, or MT cytoskeleton transgenic $N$. benthamiana plants constitutively expressing GFP fused to Arabidopsis thaliana $\alpha$-tubulin (TuaGFP plants) (Gillespie et al. 2002), GFP targeting the cortical ER (16c plants) (Ruíz et al. 1998) and a Lifeact TagRFP fusion targeting actin were also used. To visualize the Golgi apparatus, a binary vector expressing mCherry protein with a targeting signal to this structure was used (Nelson et al. 2007). In colocalization studies, every single frame was imaged consecutively for green and red fluorescence. These green and red simultaneous frames were then Z-axis-stacked to create final projections.

Chemical treatments for MT disruption were performed with colchicine (Sigma-Aldrich C9754) at the dilution of $0.5 \mu \mathrm{M}$, as described by Wright and associates (2007), unless otherwise stated. The disrupting agent was infiltrated simultaneously with the Agrobacterium solutions. Exposure of infiltrated tissue to two different supermarket brands of common nail varnish (Vera Valenti, classic; Vera Valenti, San Fernando de Henares, Spain; and Deliplus, gel acabado brillo; You Cosmetics, Gava, Spain) was achieved by directly sealing the edges of the fresh tissue to the microscope slide prior to confocal viewing. Exposure of infiltrated tissue to organic solvents (n-butyl acetate and ethyl acetate) was achieved by keeping freshly cut tissue inside a wet chamber saturated with fumes from either of these two chemicals for $1 \mathrm{~h}$ at room temperature, prior to confocal viewing. Exposure of infiltrated tissue to saturated $\mathrm{CO}_{2}$ atmosphere was achieved as described by Martiniére and associates (2013). 


\section{Immunoblot detection of proteins.}

Total protein content from infiltrated tissue was ground with a pestle in extraction buffer $(0.1 \mathrm{M}$ Tris- $\mathrm{HCl}[\mathrm{pH} 8], 10 \mathrm{mM}$ ethylenediaminetetraacetic acid, $0.1 \mathrm{M} \mathrm{LiCl}, 1 \% \beta$-mercaptoethanol, and $1 \%$ sodium dodecyl sulfate [SDS]), mixed $1: 1$ with $2 \times$ Laemmli buffer, and the sample was incubated for 10 min at $95^{\circ} \mathrm{C}$ under shaking and clarified in the bench microfuge for $5 \mathrm{~min}$ before fractionation in SDS polyacrylamide gel electrophoresis $10 \%$ gels. Gel proteins were wet-blotted in Tris-glycine buffer onto Hybond-P polyvinylidene diflouride membranes (Amersham, GE Healthcare, Buckinghamshire, U.K.) For immunological detection of GFP, a rabbit GFP polyclonal antiserum kindly donated by G. Cowan (James Hutton Institute, Dundee, U.K.) was used. For detection of 6x-HCPro, a mouse monoclonal antiserum to 6-histidines was used (SigmaAldrich, St. Louis). In the Western blot shown in Figure 5C, a rabbit polyclonal antiserum against PVY HCPro was used (Canto et al. 1995a). Blotted proteins were detected using commercial alkaline phosphatase-conjugated secondary antibodies and SigmaFast BICP/NBT substrate tablets (SigmaAldrich).

\section{Aphid transmission tests and exposure of leaf tissue to aphids.}

Transmission tests of PVY from either infected N. benthamiana fresh leaf tissue or from solutions of purified virions through stretched parafilm membranes, the latter in combination with purified HCPro, was performed using a clone of the aphid Myzus persicae and as described (Canto et al. 1995b). To expose infiltrated tissue to aphids, 50 aphids were harvested and placed under confinement on an infiltrated patch of approximately $15 \mathrm{~mm}$ in diameter for $16 \mathrm{~h}$, at room temperature in a wet chamber, prior to confocal viewing.

\section{ACKNOWLEDGMENTS}

This work was supported by a joint grant between the Spanish Ministry of Economy and Competitivity (MEC; grant ACI/2009-0855) and the Department of Science and Technology of the Government of India (grant DST/INT/SPAIN/P-9/2009); by a grant from the Rural Development Administration (RDA) of the Republic of Korea "Prediction of the impact of climate change on the outcome of diseases caused by plant RNA viruses", in cooperation with the Spanish Council for Scientific Research (CSIC); and by grant BIO2013-47940-R from MEC. T. Canto acknowledges the help of former students I. González and P. Doblas at cloning steps required to obtain some of the constructs used in this work. J. Tilsner and K. M. Wright gratefully acknowledge the advice of M. Smoker (The Sainsbury Laboratory) and technical support from W. Ridley in the generation of the red-actin transgenic $N$. benthamiana plants. We also thank M. Hallett for proofreading the manuscript.

\section{LITERATURE CITED}

Ala-Poikela, M., Goytia, E., Halkonen, T., Rajamaki, M.-L., and Valkonen, J. P. T. 2011. Helper component proteinase of the genus Potyvirus is an interaction partner of translation initiation factors $\mathrm{SIF}$ (iso) $4 \mathrm{E}$ and eIF4E and contains a 4E binding motif. J. Virol. 85:6784-6794.

Anandalakshmi, R., Pruss, G. J., Ge, X., Marathe, R., Mallory, A. C., Smith, T. H., and Vance, V. B. 1998. A viral suppressor of gene silencing in plants. Proc. Natl. Acad. Sci. U.S.A. 95:13079-13084.

Ballut, L., Drucker, M., Pugniére, M., Cambon, F, Blanc, S., Roquet, F., Candresse, T., Schmid, H.-P., Nicolas, P, Le Gall, O., and Badaoui, S. 2005. HcPro, a multifunctional protein encoded by a plant RNA virus, targets the $20 \mathrm{~S}$ proteasome and affects its enzymatic activities. J. Gen. Virol. 88:2595-2603.

Baunoch, D. A., Das, P., and Hari, V. 1990. Potato virus Y helper component is associated with amorphous inclusions. J. Gen. Virol. 71:24792482.

Berepiki, A., Lichius, A., Shoji, J.-Y., Tilsner, J., and Read, N. 2010 Factin dynamics in Neurospora crassa. Eukaryot. Cell 9:547-557.

Blanc, S., López-Moya, J.-J., Wang, R., García-Lampasona, S., Thornbury, D.-W., and Pirone, T. P. 1997. A specific interaction between coat pro- tein and helper component correlates with aphid transmission of a potyvirus. Virology 231:141-147.

Brigneti, G., Voinnet, O., Li, W. X., Ding, S. W., and Baulcombe, D. C. 1998. Viral pathogenicity determinants are suppressors of transgene silencing in Nicotiana benthamiana. EMBO (Eur. Mol. Biol. Organ.) J. 17:6739-6746.

Canto, T., Ellis, P., Bowler, G., and López-Abella, D. 1995a. Production of monoclonal antibodies to Potato virus Y helper component-protease and their use for strain differentiation. Plant Dis. 79:234-237.

Canto, T., López-Moya, J. J., Serra-Yoldi, M. T., Díaz-Ruíz, J. R., and López-Abella, D. 1995b. Different helper component mutations associated with lack of aphid transmissibility in two isolates of Potato virus Y. Phytopathology 85:1519-1524.

Canto, T., Cillo, F., and Palukaitis, P. 2002. Generation of siRNAs by TDNA sequences does not require active transcription or homology to sequences in the plant. Mol. Plant-Microbe Interact. 15:1137-1146.

Carrington, J. C., and Herndon, K. L. 1992. Characterization of the potyviral HC-Pro autoproteolytic cleavage site. Virology 187:308-315.

Carrington, J. C., Cary, S. M., and Dougherty, W. G. 1988. Mutational analysis of Tobacco etch virus polyprotein processing: cis- and transproteolytic activities of polyproteins containing the $49-\mathrm{kDa}$ proteinase. J. Virol. 62:2313-2320.

Chapman, E. J., Prokhnevsky, A. I., Gopinath, K., Dolja, V. V., and Carrington, J. 2004. Viral RNA silencing suppressors inhibit the microRNA pathway at an intermediate step. Genes Dev. 18:1179-1186.

Cheng, Y.-Q., Liu, Z.-M., Xu, J., Zhou, T., Wang, M., Chen, Y.-T., Li, H.F., and Fan, Z.-F. 2008. HC-Pro protein of sugar cane mosaic virus interacts specifically with maize ferredoxin-5 in vitro and in planta. J. Gen. Virol. 89:2046-2054.

Chung, B. Y.-W., Miller, W. A., Atkins, J. F., and Firth, A. E. 2008. An overlapping essential gene in the Potyviridae. Proc. Natl. Acad. Sci. U.S.A. 105:5897-5902.

Dielen, A.-S., Sassaki, F. T., Walter, J., Michon, T., Menard, G., Pagny, G., Krause-Sakate, R., Maia, I., Badaoui, S., Le Gall, O., Candresse, T., and German-Retama, S. 2011. The 20S proteasome $\alpha_{5}$ subunit of Arabidopsis thaliana carries and RNase activity and interacts in planta with the Lettuce mosaic potyvirus HcPro protein. Mol. Plant Pathol. 12:137-150.

Endres, M. W., Gregory, B. D., Gao, Z., Foreman, A. W., Mlotshwa, S., Ge, X., Pruss, G. J., Ecker, J. R., Bowman, L. H., and Vance, V. 2010. Two plant viral suppressors of silencing require the ethylene-inducible host transcription factor RAV2 to block RNA silencing. PLoS Pathog. 6:e1000729.

Freire, M. A. 2014. Potyviral VPg and HC-Pro proteins and the cellular translation initiation factor aIF(iso)4E interact with exoribonuclease Rrp6 and a small $\alpha$-heat shock protein. Plant Mol. Biol. Rep. 32:596-604.

García, J. A., Riechmann, J. L., and Laín, S. 1989. Proteolytic activity of the Plum pox potyvirus NIa-like protein in Escherichia coli. Virology 170:362-369.

Gillespie, T., Boevink, P., Haupt, S., Roberts, A. G., Toth, R., Valentine, T., Chapman, S., and Oparka, K. J. 2002. Functional analysis of a DNAshuffled movement protein reveals that microtubules are dispensable for the cell-to-cell movement of Tobacco mosaic virus. Plant Cell 14:12071222.

González, I., Martínez, L. L., Rakitina, D., Lewsey, M. G., Atienzo, F. A., Llave, C., Kalinina, N., Carr, J. P., Palukaitis, P., and Canto, T. 2010. Cucumber mosaic virus $2 \mathrm{~b}$ protein subcellular targets and interactions: Their significance to its RNA silencing suppressor activity. Mol. PlantMicrobe Interact. 23:294-303.

González, I., Rakitina, D., Semashko, M., Taliansky, M., Praveen, S., Palukaitis, P., Carr, J. P., Kalinina, N., and Canto, T. 2012. RNA binding is more relevant to the suppression of silencing function of Cucumber mosaic virus $2 \mathrm{~b}$ protein than nuclear localization. RNA 18:771-782.

Govier, D. A., and Kassanis, B. 1974. Evidence that a component other than the virus particle is needed for aphid transmission of Potato virus Y. Virology 57:285-286.

Guo, D., Spetz, C., Saarma, M., and Valkonen, J. P. T. 2003. Two potato proteins, including a novel RING finger protein (HIP1), interact with the potyviral multifunctional protein HCpro. Mol. Plant-Microbe Interact. 16:405-410.

Haikonen, T., Rajamäki, M.-L., Tian, Y.-P., and Valkonen, J. P. T. 2013a. Mutation of a short variable region in HCpro protein of Potato virus A affects interactions with a microtubule-associated protein and induces necrotic responses in tobacco. Mol. Plant-Microbe Interact. 26:721-733.

Haikonen, T., Rajamaki, M.-L., and Valkonen, J. P. T. 2013b. Interaction of the microtubule-associated host protein HIP2 with viral helper component proteinase is important in infection with Potato virus A. Mol. Plant-Microbe Interact. 26:734-744.

Horsch, R. B., Fry, J. E., Hoffman, N. L., Eichholtz, D., Rogers, S. G., and Fraley, R. T. 1985. A simple and general method for transferring genes into plants. Science 227:1229-1231. 
Jamous, R. M., Boonrod, K., Fuellgrabe, M. W., Ali-Shetayen, M. S., Krczai, G., and Wassenegger, M. 2011. The helper component-proteinase of the Zucchini yellow mosaic virus inhibits the Hua Enhancer 1 methyltransferase activity in vitro. J. Gen. Virol. 92:2222-2226.

Jin, Y., Ma, D., Dong, J., Jin, J., Li, D., Deng, C., and Wang, T. 2007a. HCPro of Potato virus $Y$ can interact with three Arabidopsis $20 \mathrm{~S}$ proteasome subunits in planta. J. Virol. 81:12881-12888.

Jin, Y., Ma, D., Dong, J., Li, D., Deng, C., Jin, J., and Wang, T. 2007b. The HC-Pro protein of Potato virus $Y$ interacts with NtMinD of tobacco. Mol. Plant-Microbe Interact. 20:1505-1511.

Johansen, L. K., and Carrington, J. C. 2001. Silencing on the spot. Induction and suppression of RNA silencing in the Agrobacterium-mediated transient expression system. Plant Physiol. 126:930-938.

Lakatos, L., Csorba, T., Pantaleo, V., Chapman, E. J., Carrington, J. C., Liu, Y.-P., Dolja, V.V., Calvino, L. F., López-Moya, J. J., and Burgyán, J. 2006. Small RNA binding is a common strategy to suppress RNA silencing by several viral suppressors. EMBO (Eur. Mol. Biol. Organ.) J. 25:2768-2780.

Lu, R., Malcuit, I., Moffett, P., Ruíz, M. T., Peart, J., Wu, A. J., Rathjen, J. P., Bendahmane, A., Day, L., and Baulcombe, D. C. 2003. High throughput virus-induced gene silencing implicates heat shock protein 90 in plant disease resistance. EMBO (Eur. Mol. Biol. Organ.) J. 22:5690-5699.

Maia, I. G., and Bernardi, F. 1996. Nucleic acid-binding properties of a bacterially expressed potato virus $\mathrm{Y}$ helper component protinase. J. Gen. Virol. 77:869-877.

Mangrauthia, S. K., Singh Shakya, V. P., Jain, R. K., and Praveen, S. 2009. Ambient temperature perception in papaya for Papaya ringspot virus interaction. Virus Genes 38:429-434.

Martinière, A., Bak, A., Macia, J.-L., Lautredou, N., Gargani, D., Doumayrou, J., Garzo, E., Moreno, A., Fereres, A., Blanc, S., and Drucker, M. 2013. A virus responds instantly to the presence of the vector on the host and forms transmission morphs. Elife 2:e00183.

Mérai, Z., Kerényi, Z., Kertész, S., Magda, M., Lakatos, L., and Silhavy, D. 2006. Double-stranded RNA binding may be a general plant RNA viral strategy to suppress silencing. J. Virol. 80:5747-5756.

Mlotshwa, S., Verver, J., Sithole-Niang, I., Gopinath, K., Carette, J., Van Kammen, A. B., and Wellink, J. 2002. Subcellular location of the helper component-protease of Cowpea aphid-borne mosaic virus. Virus Genes 25:207-216

Moghal, S. M., and Francki, R. I. B. 1976. Towards a system for the identification and classification of potyviruses. Virology 73:350-362.

Nakahara, K. S., Masuta, C., Yamada, S., Shimura, H., Kashihara, Y., Wada, T. S., Meguro, A., Goto, K., Tadamura, K., Sueda, K., Sekiguchi, T., Shao, J., Itchoda, N., Matsumara, T., Igarashi, M., Ito, K., Carthew, R. W., and Uyeda, I. 2012. Tobacco calmodulin-like protein provides secondary defense by binding to and directing degradation of virus RNA silencing suppressors. Proc. Natl. Acad. Sci. U.S.A. 109:10113-10118.

Nelson, B. K., Cai, X., and Nebenführ, A. 2007. A multicolored set of in vivo organelle markers for co-localization studies in Arabidopsis and other plants. Plant J. 51:1126-1136.

Pasin, F., Simón-Mateo, C., and García, J. A. 2014. The hypervariable amino-terminus of $\mathrm{P} 1$ protease modulates potyviral replication and host defense responses. PLoS Pathog. 10:e1003985.

Plisson, C., Drucker, M., Blanc, S., German-Retama, S., Le Gall, O., Thomas, C., and Bron, P. 2003. Structural characterization of HC-Pro, a plant virus multifunctional protein. J. Biol. Chem. 278:23753-23761.

Pruss, G., Ge, X., Shi, X. M., Carrington, J. C., and Vance, V. B. 1997. Plant viral synergism: The potyviral genome encodes a broad-range pathogenicity enhancer that transactivates replication of heterologous viruses. Plant Cell 9:859-868.

Rajamaki, M.-L., Kelloniemi, J., Alminaite, A., Kekarainen, T., Rabenstein, F., and Valkonen, J. P. T. 2005. A novel insertion site inside the potyvirus $\mathrm{P} 1$ cistron allows expression of heterologous proteins and suggests some P1 functions. Virology 342:88-101.

Roudet-Tavert, G., German-Retama, S., Delaunay, T., Delécolle, B., Candresse, T., and Le Gall, O. 2002. Interaction between potyvirus helper component-proteinase and capsid protein in infected plants. J. Gen. Virol. 83:1765-1770.

Ruíz, M. T., Voinnet, O., and Baulcombe, D. C. 1998. Initiation and maintenance of virus-induced gene silencing. Plant Cell 10:937-946.

Ruíz-Ferrer, V., Boskovic, J., Alfonso, C., Rivas, G., Llorca, O., LópezAbella, D., and López-Moya, J. J. 2005. Structural analysis of Tobacco etch potyvirus HC-Pro oligomers involved in aphid transmission. J. Virol. 79:3758-3765.

Sahana, N., Kaur, H., Basavaraj, Y. B., Tena, F., Jain, R. K., Palukaitis, P.,
Canto, T., and Praveen, S. 2012. Inhibition of the host proteasome facilitates Papaya ringspot virus accumulation and proteosomal catalytic activity is modulated by viral factor HcPro. PLoS One 7:e52546.

Sahana, N., Kaur, H., Palukaitis, P., Canto, T., and Praveen, S. 2014. The asparagine residue in the FRNK box of potyviral helper-component protease is critical for template function and subcellular localization. J. Gen. Virol. 95:1167-1177.

Shiboleth, Y. M., Haronsky, E., Leibman, D., Arazi, T., Wassenegger, M., Whitham, S. A., Gaba, V., and Gal-On, A. 2007. The conserved FRNK box in HC-Pro, a plant viral suppressor of gene silencing, is required for small RNA binding and mediates symptom development. J. Virol. 81:13135-13148

Sorel, M., García, J. A., and German-Retana, S. 2014. The Potyviridae cylindrical inclusion helicase: A key multipartner and multifunctional protein. Mol. Plant-Microbe Interact. 27:215-226.

Tena, F., González, I., Doblas, P., Rodríguez, C., Sahana, N., Kaur, H., Tenllado, F., Praveen, S., and Canto, T. 2013. The influence of cis-acting $\mathrm{P} 1$ protein and translational elements on the expression of Potato virus $Y$ HCPro in heterologous systems and its suppression of silencing activity. Mol. Plant Pathol. 14:530-541.

Thornbury, D. W., Hellmann, G. M., Rhoads, R. E., and Pirone, T. P. 1985 Purification and characterization of potyvirus helper component. Virology 144:260-267.

Torrance, L., Andreev, I. A., Gabrenaite-Verhovskaya, R., Cowan, G., Mäkinen, K., and Taliansky, M. E. 2006. An unusual structure at one end of potato potyvirus particles. J. Mol. Biol. 357:1-8.

Urcuqui-Inchima, S., Walter, J., Drugeon, G., German-Retama, S., Haenni, A-L., Candresse, T., Bernardi, F., and Le Gall, O. 1999. Potyvirus helper component-proteinase self-interaction in the yeast two-hybrid system and delineation of the interaction domain involved. Virology 258:95-99.

Urcuqui-Inchima, S., Maia, I. G., Arruda, P., Haenni, A.-L., and Bernardi, F. 2000. Deletion mapping of the potyviral helper component-proteinase reveals two regions involved in RNA binding. Virology 268:104-111.

Valli, A., Martín-Hernández, A. M., López-Moya, J. J., and García, J. A. 2006. RNA silencing suppression by a second copy of the P1 serine protease of Cucumber vein yellowing ipomovirus, a member of the Family Potyviridae that lacks the cysteine protease HCPro. J. Virol. 80:10055-10063.

Vargasson, J. M., Szittya, G., Burgyan, J., and Hall, T. M. 2003. Size selective recognition of siRNAs by an RNA silencing suppressor. Cell 115:799-811.

Verchot, J., and Carrington J. C. 1995a. Debilitation of plant potyvirus infectivity by $\mathrm{P} 1$ proteinase-inactivating mutations and restoration by second -site modifications. J. Virol. 69:1582-1590.

Verchot, J., and Carrington J. C. 1995b. Evidence that the potyvirus P1 protein functions as an accessory factor for genome amplification. J. Virol. 69:3668-3674.

Verchot, J., Koonin, E. V., and Carrington, J. C. 1991. The 35-kDa protein from the $\mathrm{N}$-terminus of the potyviral polyprotein functions as a third virus-encoded proteinase. Virology 185:527-535.

Wei, T., and Wang, A. 2008. Biogenesys of cytoplamic membranous vesicles for plant potyvirus replication occurs at endoplasmic reticulum exi sites in a COPI- and CPII-dependent manner. J. Virol. 82:12252-12264.

Wei, T., Huang, T.-S., McNeil, J., Laliberté, J.-F., Hong, J., Nelson, R. S. and Wang, A. 2010a. Sequential recruitment of the endoplasmic reticulum and chloroplasts for plant potyvirus replication. J. Virol. 84:799-809.

Wei, T., Zhang, C., Hong, J., Xiong, R., Kasschau, K. D., Zhou, X., Carrington, J. C., and Wang, A. 2010b. Formation of complexes at plasmodesmata for potyvirus intercellular movement is mediated by the viral protein P3N-PIPO. PLoS Pathog. 6:e1000962.

Wei , T., Zhang, C., Hou, X., Sanfacon, H., and Wang, A. 2013. The SNARE protein Syp71 is essential for Turnip mosaic virus infection by mediating fusion of virus-induced vesicles with chloroplasts. PLoS Pathog. 9:e1003378.

Wright, K., Wood, N. T., Roberts, A., Chapman, S., Boevink, P., MacKenzie, K. M., and Oparka, K. 2007. Targeting of TMV movement protein to plasmodesmata requires actin/ER network: Evidence from FRAP. Traffic 8:21-31.

Zheng, H., Yan, F., Lu, Y., Sun, L., Lin, L., Cai, L., Hou, M., and Chen, J. 2011. Mapping the self-interacting domains of TuMV HC-Pro and the subcellular localization of the protein. Virus Genes 42:110-116.

Zilian, E., and Maiss, E. 2011. Detection of plum pox potyviral proteinprotein interactions in planta using an optimized mRFP-based bimolecular fluorescence complementation system. J. Gen. Virol. 92:2711-2723. 